RECEIVED
APR 231998
OSTI

OAK RIDGE NATIONAL LABORATORY
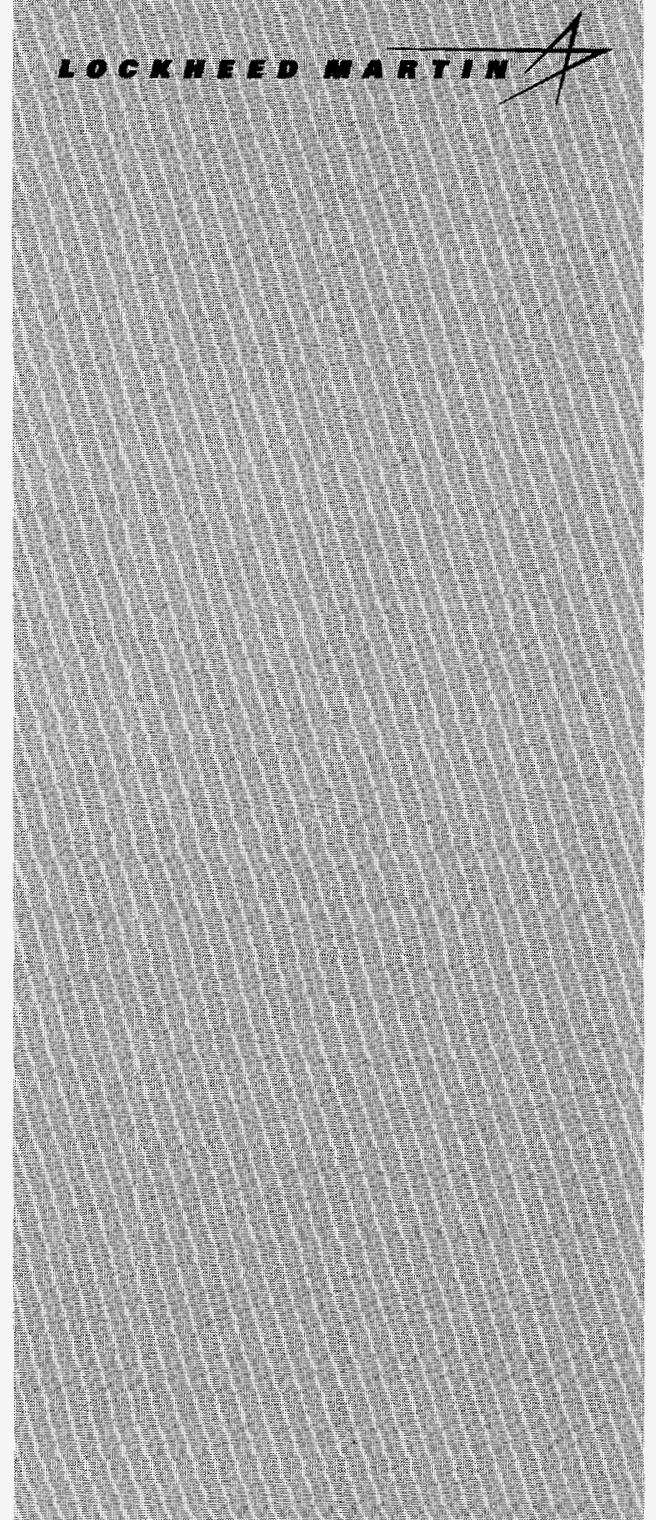

NAYACED WO OPEATTEO BY LOCKHEED MARIU ENERGY RESEARCH CORPORATIOH FOA THE UITED STATES DEPARTMENT OF ENERGY

\section{Humanitarian Mine Detection By Acoustic Resonance}

S. W. Kercel

\section{MASTER}

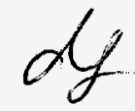


This report has been reproduced directly from the best available copy.

Available to DOE and DOE contractors from the Office of Scientific and Technical Information, P.O. Box 62. Oak Ridge. TN 37831: prices available from (423) 576-8401, FTS 626-8401.

This report was prepared as an account of work sponsored by an agency of the United States Government. Neither the United States Government nor any agency thereof, nor any of their employees. makes any warranty. express or implied. or assumes any legal liability or responsibility for the accuracy. completeness. or usefulness of any information. apparatus, product. or process disclosed, or represents that its use would not intringe privately owned rights. Reference herein to any specific commercial product, process, or service by trade name, trademark. manufacturer, or otherwise, does not necessarily constitute or imply its endorsement, recommendation, or favoring by the United States Government or any agency thereof. The views and opinions of authors expressed herein do not necessarily state or reflect those of the United States Government or any agency thereot. 


\section{DISCLAIMER}

Portions of this document may be illegible electronic image products. Images are produced from the best available original document. 


\title{
HUMANITARIAN MINE DETECTION BY ACOUSTIC RESONANCE
}

\author{
S. W. Kercel \\ Instrumentation and Controls Division
}

\section{Date Published-March 1998}

Research sponsored by the Laboratory Directed Research Program of Oak Ridge National Laboratory.

\author{
Prepared by \\ Oak Ridge National Laboratory \\ Oak Ridge, Tennessee 37831-6285 \\ Managed by \\ LOCKHEED MARTIN ENERGY RESEARCH CORP. \\ for the \\ U.S. DEPARTMENT OF ENERGY \\ under contract number DE-AC05-960R22424
}




\section{CONTENTS}

LIST OF FIGURES $\ldots \ldots \ldots \ldots \ldots \ldots \ldots \ldots \ldots \ldots \ldots \ldots \ldots \ldots \ldots$ ii

EXECUTIVE SUMMARY $\ldots \ldots \ldots \ldots \ldots \ldots \ldots \ldots \ldots \ldots \ldots \ldots \ldots \ldots$

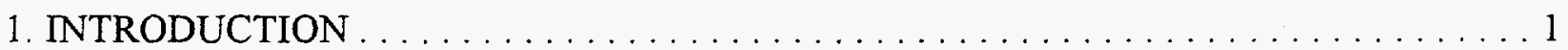

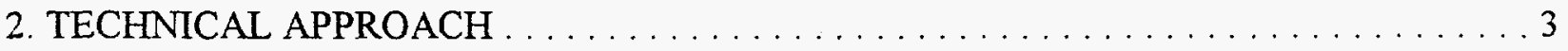

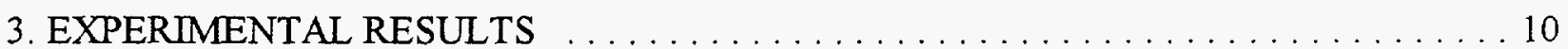

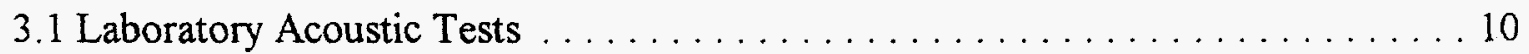

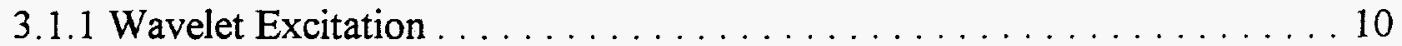

3.1 .2 Swept Sinusoid . . . . . . . . . . . . . . . . . . . . . 15

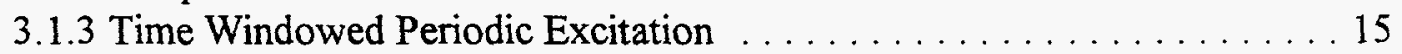

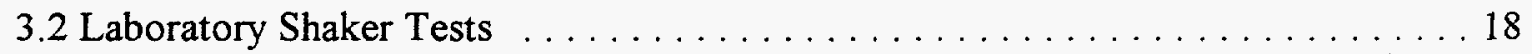

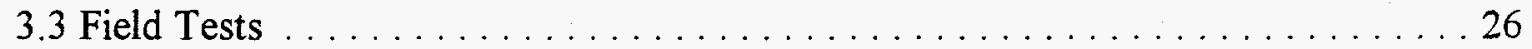

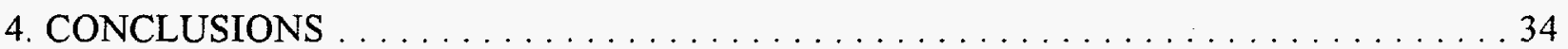

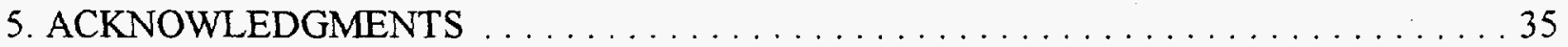

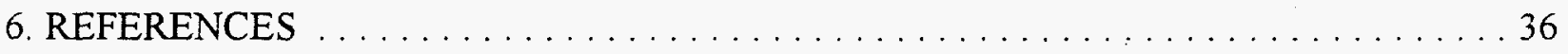




\section{LIST OF FIGURES}

Figure Page

1 Basic Experimental Setup . . . . . . . . . . . . . . . . . . . . . 4

2 Geometries for Underground Experiments $\ldots \ldots \ldots \ldots \ldots \ldots \ldots \ldots$

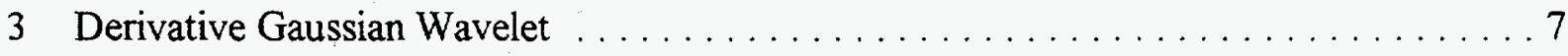

4 Power Spectrum of Derivative Gaussian Wavelet $\ldots \ldots \ldots \ldots \ldots \ldots \ldots \ldots$

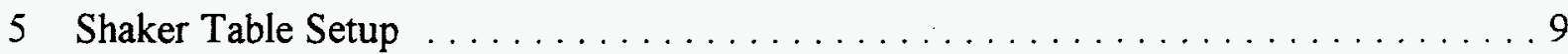

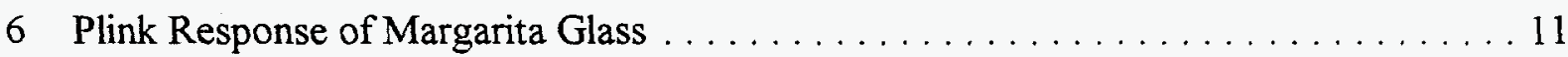

7 Spectrum Due to Haar Wavelet Excitation $\ldots \ldots \ldots \ldots \ldots \ldots \ldots \ldots \ldots \ldots \ldots \ldots \ldots \ldots \ldots$

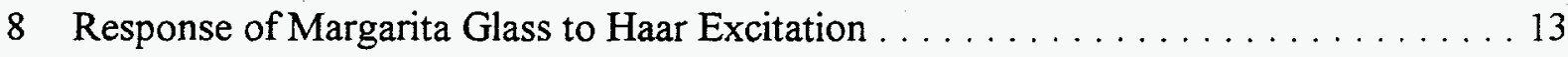

9 Geometry of Wavelet Excitation Experiment $\ldots \ldots \ldots \ldots \ldots \ldots \ldots \ldots \ldots$

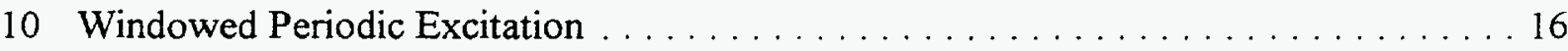

11 Response of Margarita Glass to Windowed Periodic Excitation $\ldots \ldots \ldots \ldots \ldots 17$

12 Plink Test of Wine Glass Mounted on Shaker Table . . . . . . . . . . . . . . 20

13 Response of Empty Shaker Table to $0.2 \mathrm{~g}$ Acceleration $\ldots \ldots \ldots \ldots \ldots \ldots \ldots$

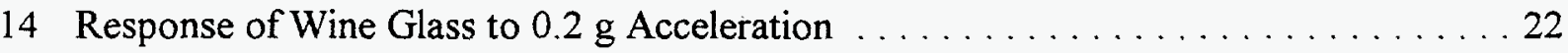

15 Plink Test of Plastic Mine ... . . . . . . . . . . . . . . . . . . . . . . . 23

16 Shaker Test of US NM-M14 Anti-Personnel Mine $\ldots \ldots \ldots \ldots \ldots \ldots \ldots \ldots \ldots$

17 Shaker Test of Soviet PMN Anti-Personnel Mine . . . . . . . . . . . . . . . 25

18 Frequency Response to Open Air Excitation . . . . . . . . . . . . . . . . . . 27

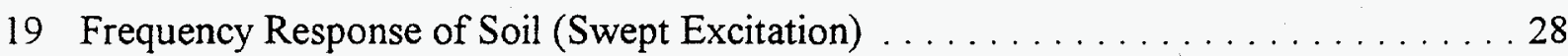

20 Frequency Response of Soil (Discrete Excitation) . . . . . . . . . . . . . . . 29 
Figure

21 Effect of Soil on Plink Response $\ldots \ldots \ldots \ldots \ldots \ldots \ldots \ldots \ldots \ldots \ldots \ldots \ldots$

22 Response of Buried Resonant Object to Impulse Excitation . . . . . . . . . . . . 32

23 Response of Backfilled Hole to Impulse Excitation $\ldots \ldots \ldots \ldots \ldots \ldots$ 


\section{EXECUTIVE SUMMARY}

The JASON Committee at MITRE Corp. was tasked by DARPA to inquire into suitable technologies for humanitarian mine detection. Acoustic resonance was one of the very few technologies that the JASONs determined might be promising for the task, but was as yet unexplored at the time that they conducted their inquiry. The objective of this Seed Money investigation into acoustic resonance was to determine if it would be feasible to use acoustic resonance to provide an improvement to present methods for humanitarian mine detection.

As detailed in this report, acoustic resonance methods do not appear to be feasible for this task. Although acoustic resonant responses are relatively easy to detect when they exist, they are very difficult to excite by the non-contact means that must be used for buried objects. Despite many different attempts, this research did not discover any practical means of using sound to excite resonant responses in objects known to have strong resonances. The shaker table experiments did see an effect that might be attributable to the resonance of the object under test, but the effect was weak, and exploited the a priori knowledge of the resonant frequency of the object under test to distinguish it from the background. If experiments that used objects known to have strong acoustic resonances produced such marginal results, this does not seem to be a practical method to detect objects with weak resonances or non-existent resonances.

The results of this work contribute to the ORNL countermine initiative. ORNL is exploring several unconventional mine detection technologies, and is proposing to explore others. Since this research has discovered some major pitfalls in non-metallic mine detection, this experience will add realism to other strategies proposed for mine detection technologies. The experiment provided hands-on experience with inert plastic mines under field conditions, and gives ORNL additional insight into the problems of developing practical field-deployable methods of mine detection. 


\section{INTRODUCTION}

Countermine has several different meanings. These different meanings define several distinctly different problems (military, humanitarian, commercial), with different tradeoffs and constraints. These problems demand several different (and not necessarily compatible) solutions, and have motivated several different courses of action.

Historically, the military countermine problem has motivated the most action. The US Army's Communications and Electronics Command - Night Vision and Electronic Sensors Directorate (CECOM-NVESD) says that the objective in countermine is secure unrestricted mobility for US forces. Although mines may incidentally be detected and/or cleared in the process, neither of these is the objective; the specific objective of countermine operations is to minimize delay for forces transiting a mined area. The US Army's countermine efforts, going back at least as far as the first World War, have been specifically aimed at this objective. ${ }^{1}$

Recently, the humanitarian countermine problem has motivated the most discussion. The humanitarian problem derives from the fact that irregular forces use mine warfare primarily to terrorize civilian populations. The media are full of heart rending stories of maimed children in third world countries. The terror is fairly widespread; the oft-quoted statistic is that $80-110$ million unexploded uncleared mines are lurking out there, waiting for their victims. ${ }^{2}$ Several international Non-Government Organizations (NGO) with very sparse resources are making a limited effort to remove mines from civilian areas, but only about 100,000 per year are actually removed. ${ }^{3}$ However, the primary response to the humanitarian countermine problem has been the attempt by well-meaning lawmakers to simply legislate the tens of millions of unexploded uncleared mines out of existence. ${ }^{4}$

Without much notice in the media, a new demining problem has emerged, mostly as a consequence of the Gulf War of 1990-91. This new problem is the commercial demining problem. Its distinction derives from the fact that while the victims are civilians, they are civilians with money. Nation-states and multinational corporations who are being denied access to needed resources are supporting elaborate demining programs run by commercial contractors. The commercial approach uses elaborate arrays of multiple sensors, and very large computers to postprocess the resulting torrent of data in search of mine signatures.

It is noteworthy that these problems are distinct. Military mine detectors must operate day or night, and must operate at high speed. Probability of detection $\left(\mathrm{P}_{\mathrm{d}}\right)$ must be high, but not so high as to cause a high probability of false alarm $\left(\mathrm{P}_{\mathrm{fa}}\right)$. High speed is not as crucial in humanitarian demining, and the occasional false positive is tolerable. Low cost and simplicity of operation are major issues for humanitarian deminers. Furthermore, since the work is performed by civilian contractors, $\mathrm{P}_{\mathrm{d}}$ must be as near to $100 \%$ as possible. ${ }^{5}$ Commercial deminers require extremely high $\mathrm{P}_{\mathrm{d}}$, low $\mathrm{P}_{\mathrm{fa}}$, off-the-shelf technology and high speed all at once. However, cost is a minor issue for their well-heeled clients. 
The three problems have common threads. The objective of mine laying is to deny access, access of conventional military forces to desired positions, access of third world farmers to their fields, or access of sheikhs to their oil wells. For all three problems, trained dogs are effective mine detectors. However, the use of dogs is costly and presents enormous logistical problems. ${ }^{3}$ Nobody is satisfied with present mine detection methods. For practically all sensor technologies, the fundamental tradeoff is that a tolerably high $P_{d}$ implies an intolerably high $P_{f a}$.

The Defense Advanced Programs Research Agency (DARPA) characterizes the current state of mine detection technology with the observation that "breakthrough technologies are needed." Using the proposition that if dogs can find mines, then they are findable, DARPA argues that breakthroughs are realizable. However, breakthroughs will not be achieved by looking at the past and doing the same old things harder. To quote Sir Francis Bacon's sage advice, "If we are to achieve results never before accomplished, we must employ methods never before attempted."

Although the humanitarian mine detection problem is outside the traditional mission of the military, and remains unsolved, the problem persists. There are many tens of millions of unexploded mines planted throughout the world, and interest in developing a cheap electronic mine detector is growing. In keeping with this interest, the JASON Committee at MITRE Corp. was tasked by DARPA to investigate suitable technologies for humanitarian mine detection. ${ }^{6}$

Acoustic resonance was one of the very few technologies that the JASONs thought would be promising for humanitarian mine detection, but was as yet unexplored at the time that they conducted their study. The JASONs assumed that all mines have membranes, internal openings, empty spaces, etc., that should have natural mechanical resonances in the $5-50 \mathrm{kHz}$ range. Since rocks, tree roots and the like have no hollow spaces, they do not have strong mechanical resonances as mines might be expected to have. The hope was that an incident broadband acoustic wave might cause a mine to vibrate at its resonant frequencies, but not impart enough energy to detonate the mine, and that the vibration signatures should be quite distinctive to identify the object as a mine.

The objective of Oak Ridge National Laboratory's (ORNL) preliminary investigation of this technique was to determine if swept acoustic resonance would provide an improvement to present procedures for humanitarian demining. Practically all the mines presently deployed, and the object of humanitarian mine detection, have some metal content. The problem is that the small metal content cannot be distinguished from other small objects such as spent bullets. The present procedure is to detect the presence of metal with an AN/PSS-12 metal detector, and then probe with a short stick to identify the object.

The JASONs hoped that a device based on acoustic signature might be a safer (albeit imperfect) alternative to simply probing with a stick. The AN/PSS-12 can find the center of the location of the suspected object fairly precisely, and it can indicate whether or not there are other metal objects in the near vicinity. Using this information, the deminer would know where to put a 
pair (transmit and receive, about a foot apart) of ground-contact transducers. The idea would be that the target would be between the transducers, but not in contact with either one. Such a technology would be better than the present practice, in which the deminer uses the information from the AN/PSS-12 to know where to insert the stick into the ground.

This approach was considered promising because it offered several advantages. It avoids the 'standoff' problem, by not standing off. Using the information already available to the deminer, the transducers are in contact with the ground at safe spots, as suggested in the JASONs report. There is no 'ground bounce' and the attenuation and ringing that go with it. Also, this approach does not depend on reflection. It depends on the notion that a large class of plastic mines should produce a readily detectable resonant response. The objective of this research was to investigate whether or not this is so.

Swept acoustic resonance was investigated by researchers in ORNL's Instrumentation and Controls Division under the Laboratory Directed Research and Development Seed Money program. Unhappily, as recounted in the technical details of this report, swept acoustic resonance does not appear to be a practical method of humanitarian mine detection. Typical small plastic anti-personnel mines were tested, and were found to not exhibit detectable acoustic resonances. Also, non-metal objects known to have strong acoustic resonances were tested with a variety of excitation techniques, and no practical method of exciting a consistently detectable resonance in a buried object was discovered.

\section{TECHNICAL APPROACH}

The basic experimental setup is shown in Figure 1. Excitation waveforms were generated by a LeCroy 9112 Arbitrary Function Generator (DOE Tag Number X186424). The generator was used to drive a Harmon Kardon HK-6200 amplifier (Serial Number S150-05667). The amplifier was used to drive an ElectroVoice 8-Ohm reproducer (Model DH1A, Serial Number 86690). The beam of the acoustic output of the reproducer was narrowed by an Electro Voice HP420 horn. The horn was heavily shielded on the sides and back to minimize the energy being transmitted off-axis.

The detection scheme detected responses at audio and ultrasonic frequencies from the object under excitation. The pickup was a B\&K 4133 scientific microphone element with a flat response to $40 \mathrm{kHz}$. This was coupled to a B\&K 2639 preamplifier and a B\&K 2807 power supply. The output of the B\&K setup was analyzed by a Hewlett-Packard $3561 \mathrm{~A}$ spectrum analyzer (Serial Number 2338A00727). The pickup was directional and was pointed at the object under excitation. 


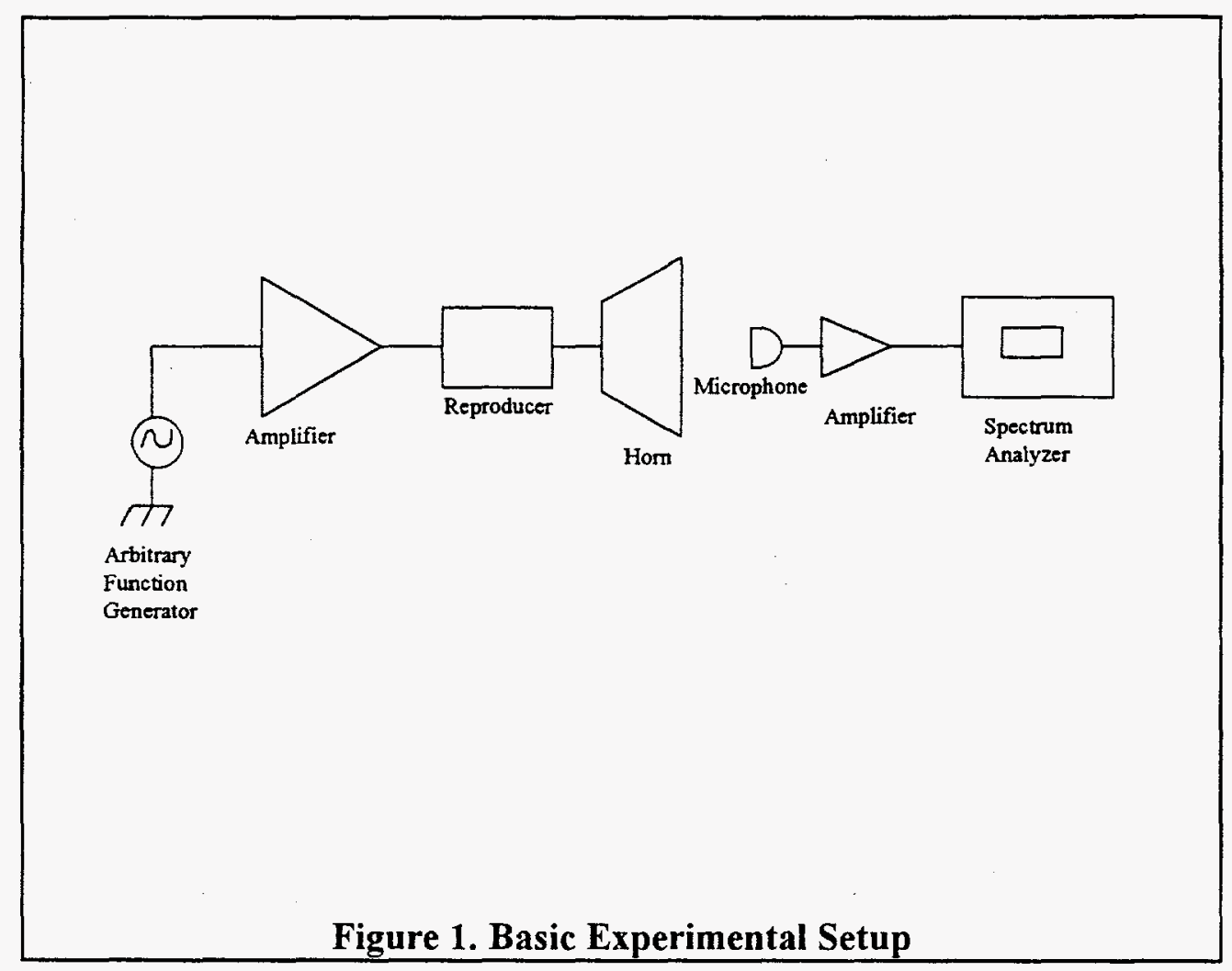

The setup was used in a variety of configurations. The object under excitation was placed about a foot in front of the aperture of the horn. The receiving pickup was pointed at the object under excitation. In the laboratory, several different alignments of the receiving microphone and the transmitting horn were tried.

When used for underground measurements, two geometries were tried. One geometry is shown in Figure 2. The horn was placed in an open hole and covered with a sound deadening tarp folded into many layers. The object under excitation was placed in a small plastic canister and buried with its center about a foot and a half in front of the aperture of the horn. The receiving pickup was placed in a small hole such that it aligned with the object under excitation, and the hole was covered with another sound deadening tarp. In the other underground geometry, the horn was placed with its major axis vertical, and with the aperture directly butted to the ground surface.

The initial technical approach is based on the observation that a wavelet function should be superior to a simple impulse as a driving function. Unlike an impulse, a wavelet has no DC component, and very little energy at low frequencies. Furthermore, the wavelet function can be controlled so as to concentrate its energy into a specific band of frequencies. 
For example, a derivative Gaussian wavelet pulse of 32-microseconds support-length has its energy concentrated in the $5-50 \mathrm{kHz}$ region (Figures 3 and 4). The pulse can be repeated at a $1 \mathrm{kHz}$ repetition rate, and treated as repeated trials. A two-minute burst of such pulses constitutes $100 \mathrm{~K}$ repeated trials.

In practice, the derivative Gaussian wavelet does not work especially well. As seen in Figure 4, most of the energy content is in the $30-50 \mathrm{kHz}$ band, and the amplifier/speaker scheme rolls off above $20 \mathrm{kHz}$. The effect results in the speaker output being spread out in time. To overcome this, most of the "wavelet excitation" experiments were done with a Haar wavelet of the shortest possible duration. That is, the signal generated by the arbitrary function generator was a single value of +1 followed by a single value of -1 with the remainder of the period taken as zero values. When convolved with the amplifier/speaker response, the resulting speaker output looks approximately like a derivative Gaussian wavelet.

Figure 3 shows that the energy of the wavelet excitation is extremely low. The figure indicates one period of a periodic derivative Gaussian wavelet, plotted to scale. The Haar wavelet excitation is even narrower in duration, while using the same period. Although the wavelet excitation has its energy distributed in a desirable frequency spectrum, the total energy in the spectrum is very small. Experimental results indicate that the wavelet excitation failed to excite resonances in the target, and it is suspected that the waveform lacked the energy. A variety of other waveforms were also used, as is discussed in the experimental results.

In addition, the researchers attempted to excite resonances in non-metallic resonant objects by mechanically shaking the objects. The setup is shown in Figure 5. The resonant object was mounted on a Model PM 250 shaker table (manufactured by MB Dynamics, Bedford Heights, Ohio), and shaken at various frequencies and accelerations. The detection setup was the same as was used for the acoustic excitation experiments. 


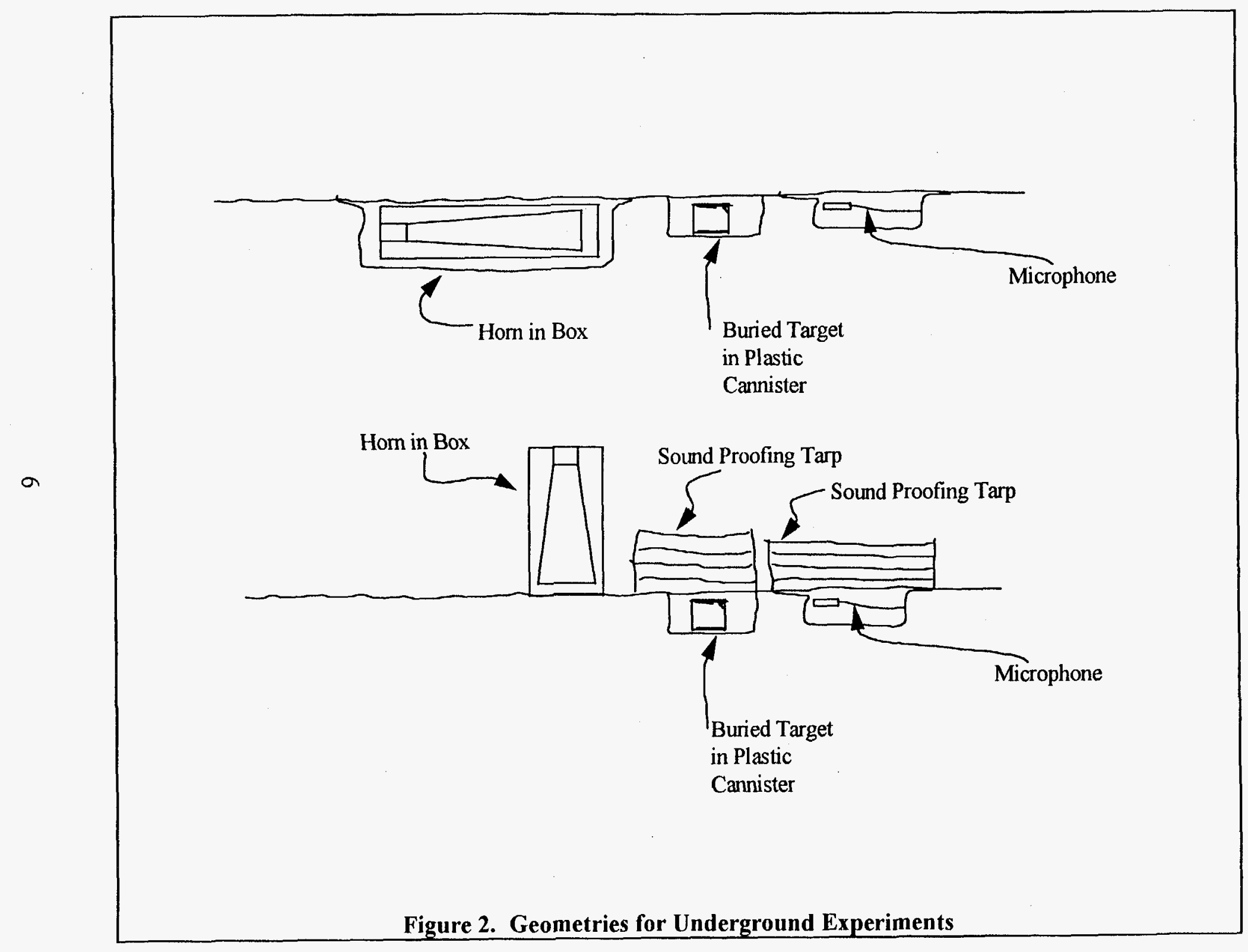




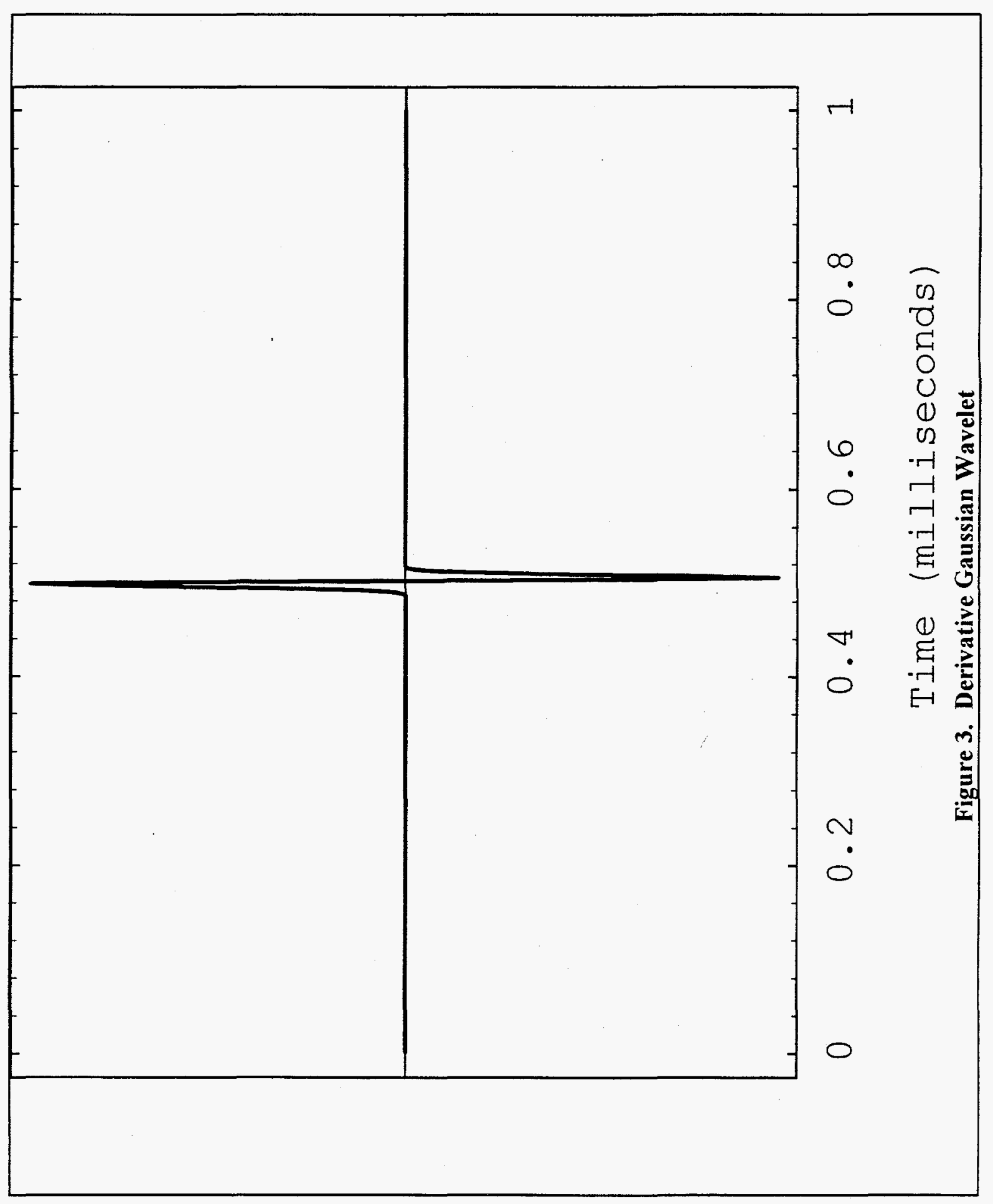




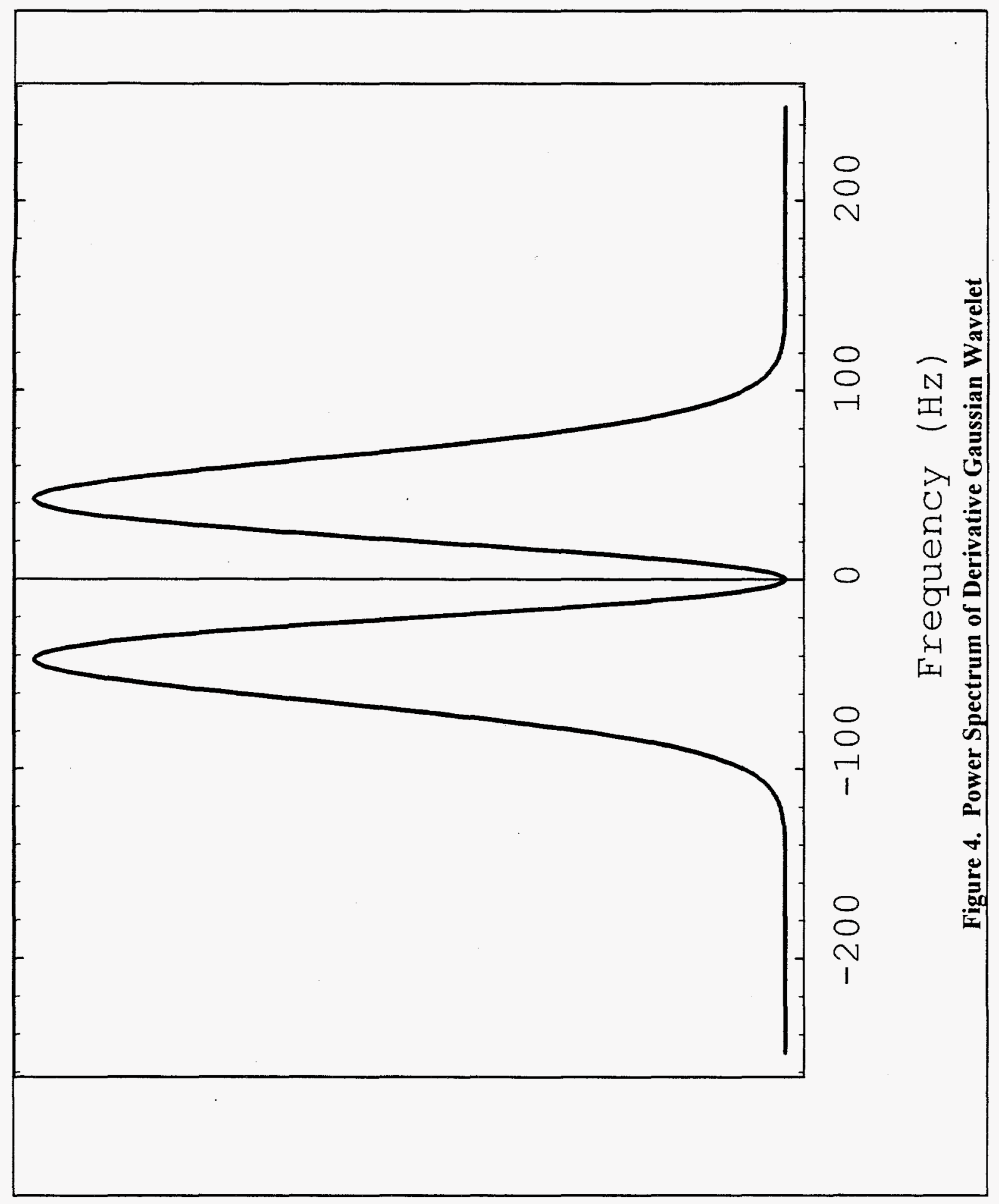




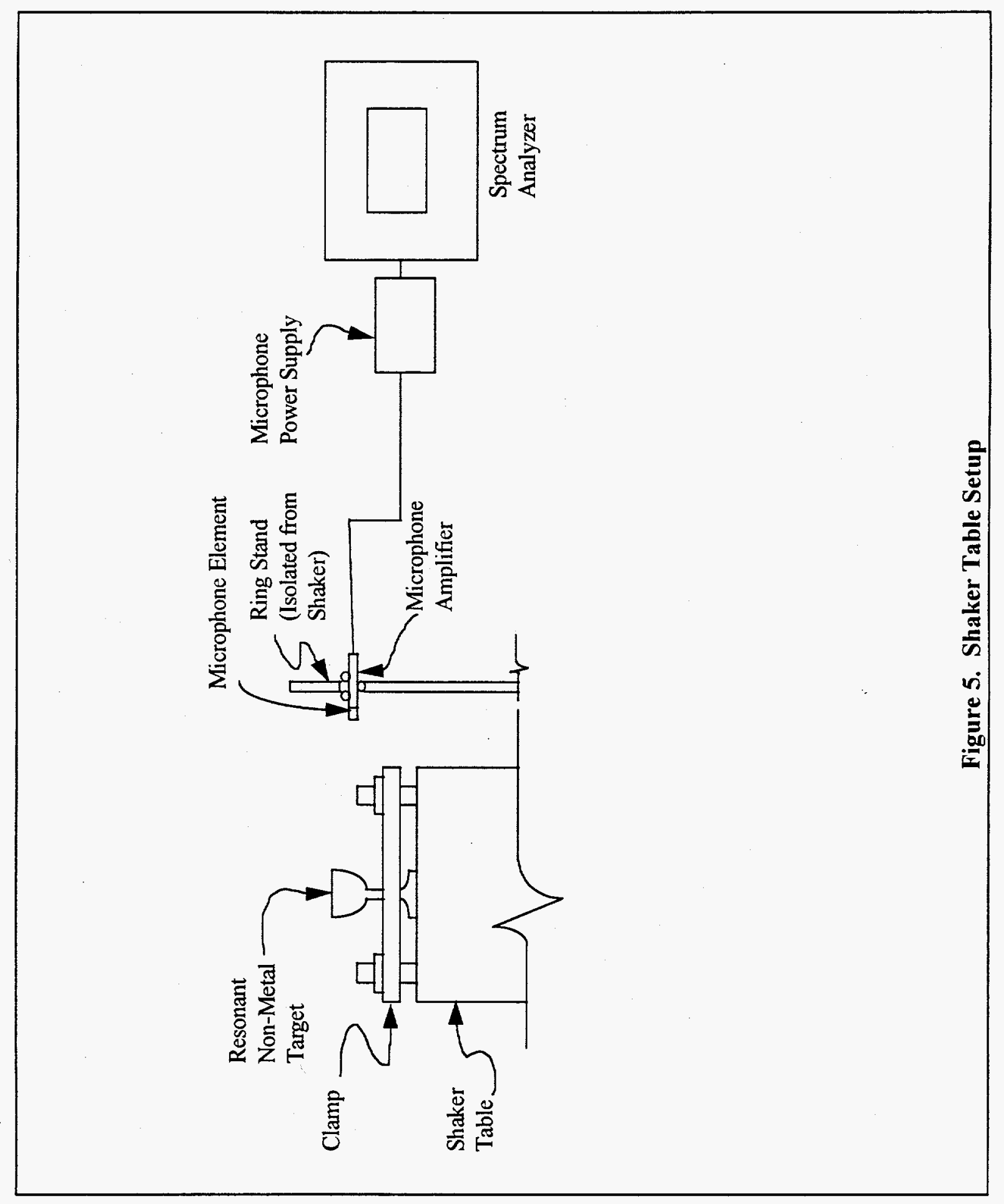




\section{EXPERTMENTAL RESULTS}

Much of the work in this project used objects that were known to have strong resonances. The objective of the research was to determine if it was feasible to use acoustic resonances in non-metallic structures to detect mines. If the technique were feasible, it should have been very effective at detecting non-metallic structures with known strong resonances.

Detecting resonant responses is not a problem. Plinking a wine glass with a finger excites a strong resonant response, easily observable by the detection setup. It can even be detected through several feet of dirt. The problem is that a mine detector cannot directly plink a mine.

Three possible methods of exciting resonances in buried objects were investigated. The first was straightforward acoustic excitation. The second was striking the ground with a strong impulse. The third was by steady state shaking. None of these methods excited consistently detectable resonances.

\subsection{Laboratory Acoustic Tests}

The first question is, can acoustic resonances in non-metal objects be detected at all with the experimental apparatus? As seen in Figure 6, the answer is clearly yes. Figure 6 is the response of a margarita glass to a finger plink. The response is seen to include peaks in the vicinity of 1150 $\mathrm{Hz}, 1950 \mathrm{~Hz}$, and $3400 \mathrm{~Hz}$. There is also a strong resonance at $5200 \mathrm{~Hz}$.

\subsubsection{Wavelet Excitation}

The JASON report suggested exciting the object with an impulse wavelet should do better. None of its energy is wasted at DC. Given the encouraging results at Figure 6, it is tempting to think that one should simply select a wavelet whose energy is concentrated in the 1-2 $\mathrm{kHz}$ band, beam the acoustic wavelet energy at the target, and observe the resulting peaks.

Selecting the wavelet is not difficult, as is shown in Figure 7. A Haar wavelet with a support length of 480 microseconds is used for excitation. With no object in the field of view, it is clear that much of the excitation energy is distributed in the $1-2 \mathrm{kHz}$ band.

Unfortunately, this excitation lacks the energy to excite the resonance of the margarita glass. Figure 8 is the response with the margarita glass in the excitation beam. It is practically indistinguishable from Figure 7. Resonance peaks do not stand out. The microphone is off-axis as shown in Figure 9. This is to prevent the excitation from overshadowing the resonant response. None of the many variations of this experiment excited a detectable resonance response. 


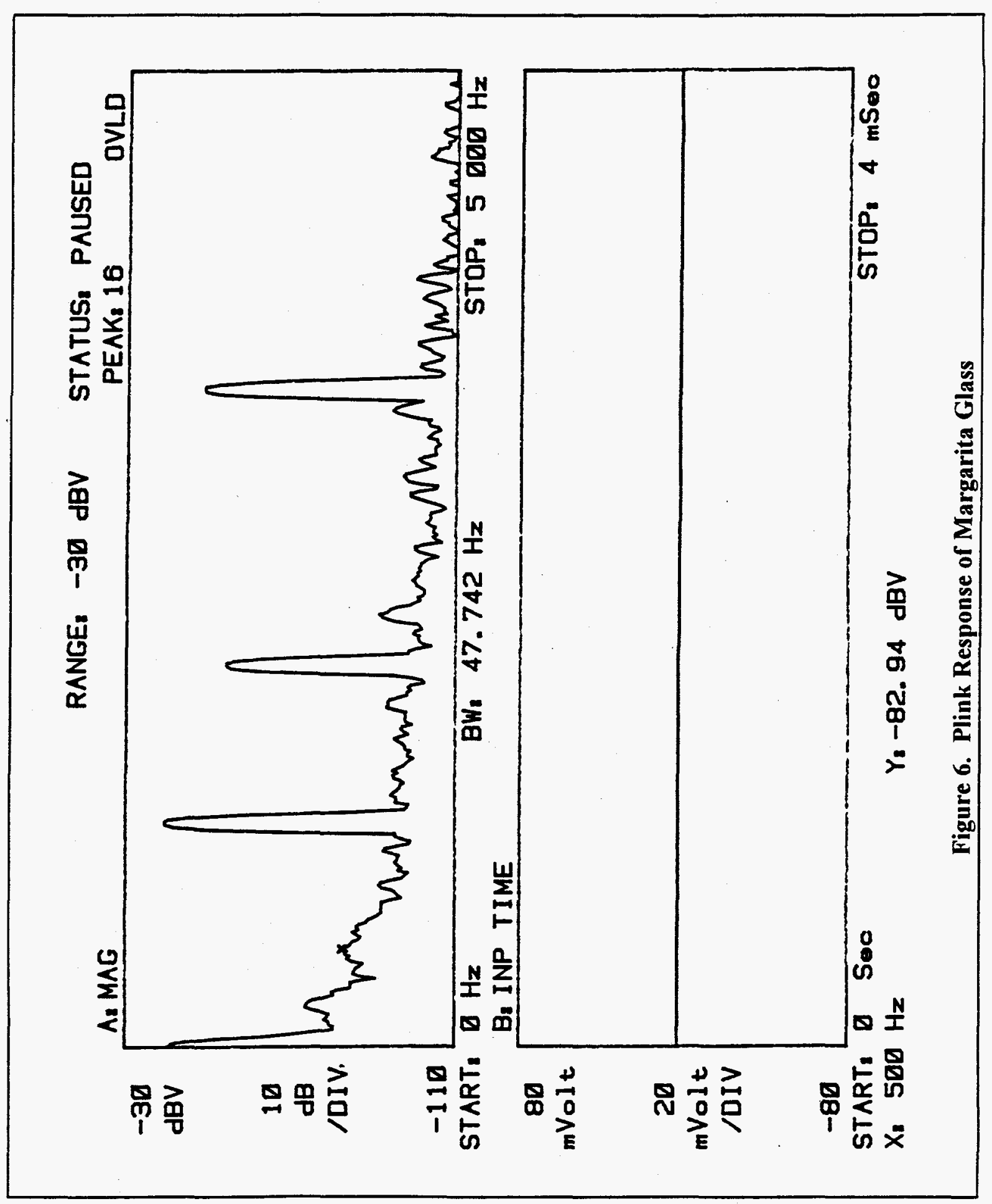




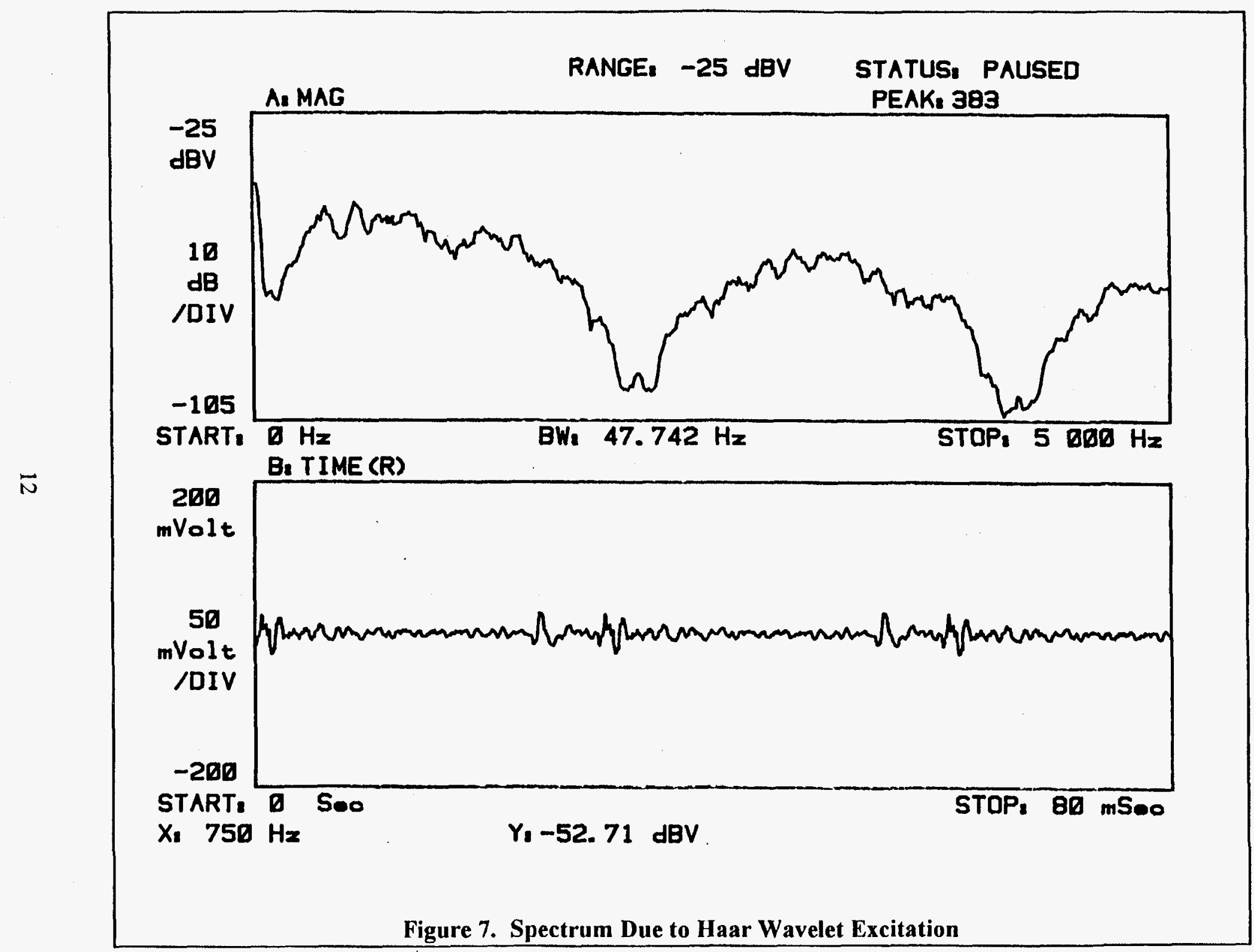




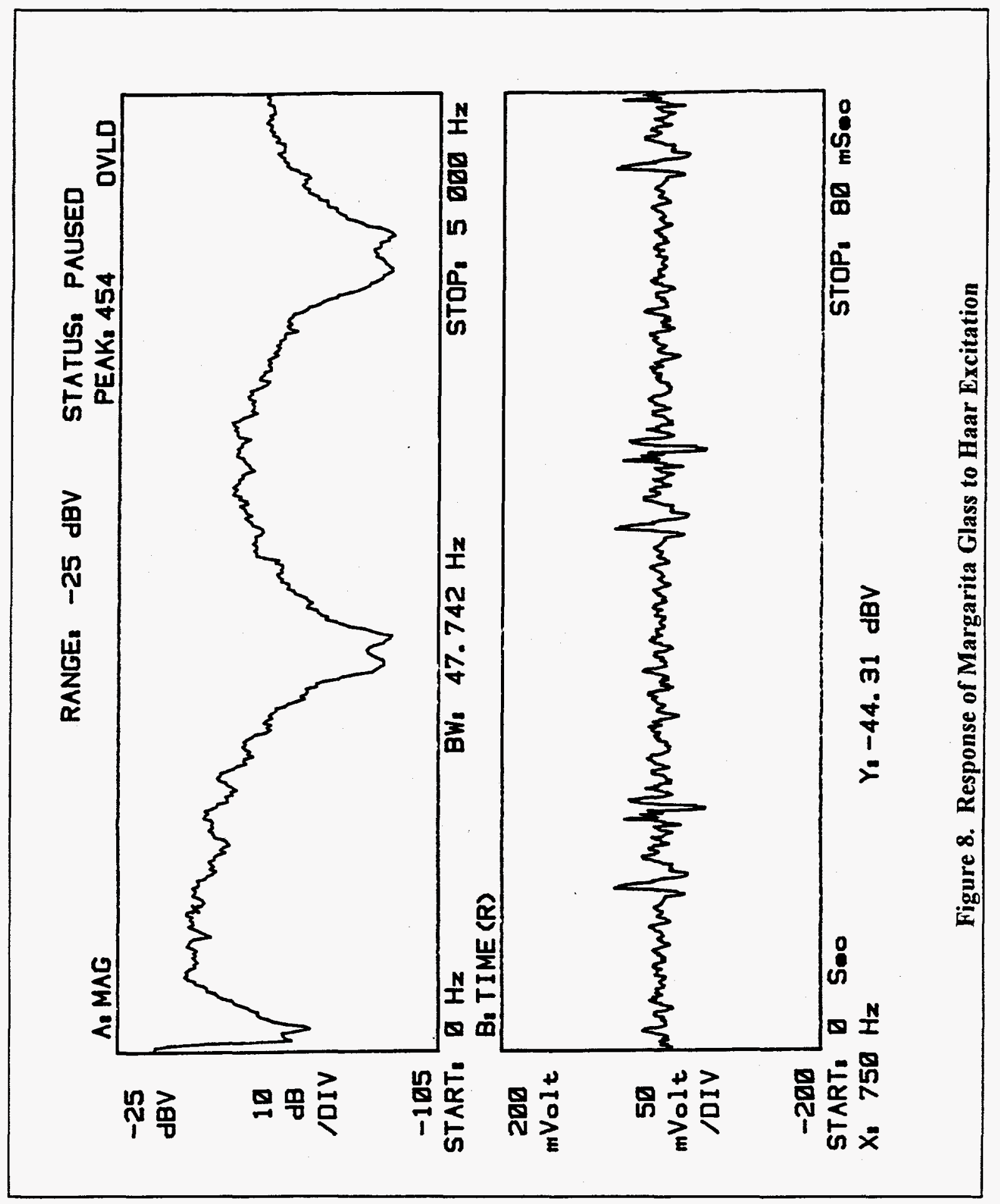




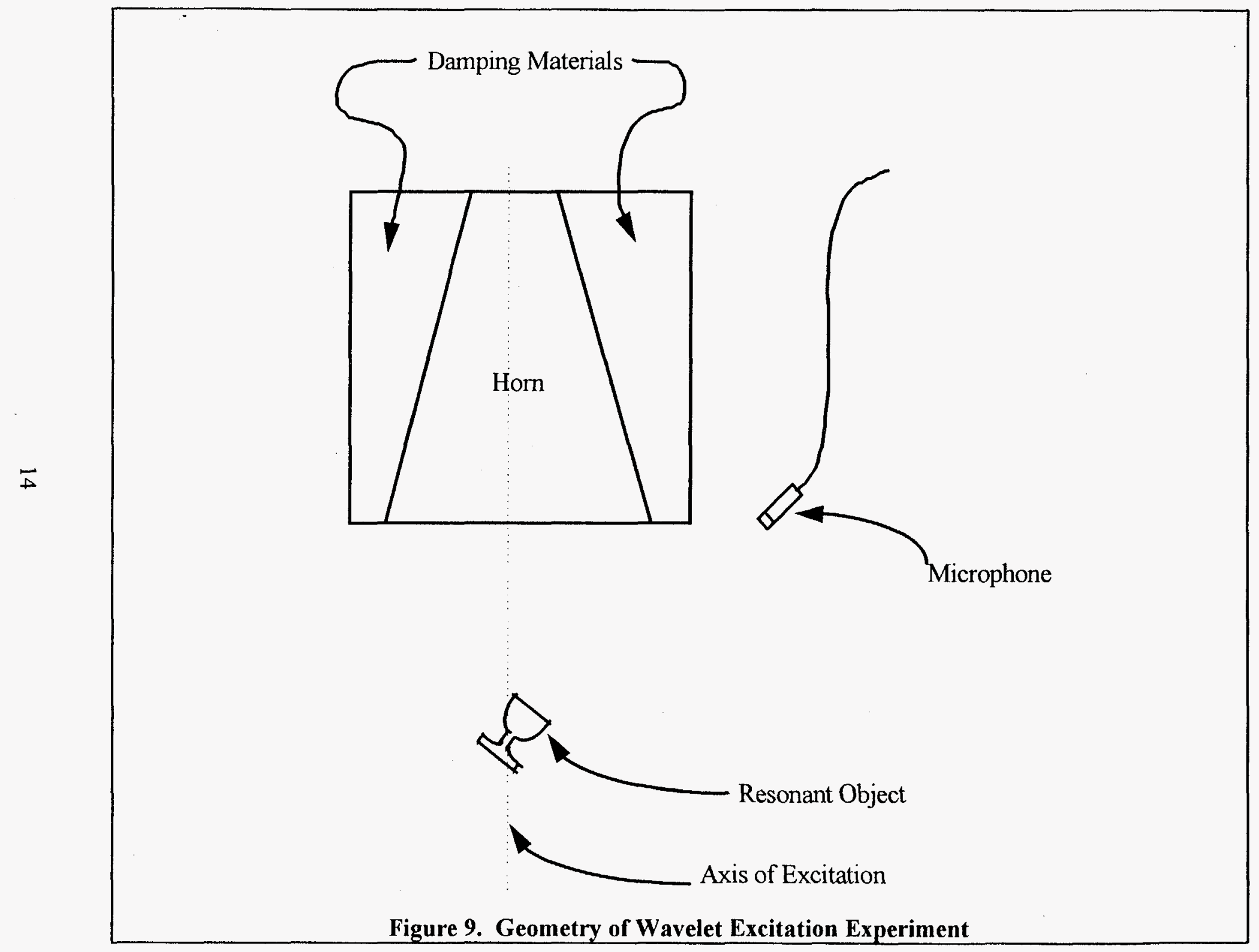




\subsubsection{Swept Sinusoid}

The disappointing results thus far suggest that a more energetic wave might be more successful. A swept sinusoid is such a wave. The excitation is slowly swept from 100 to $4000 \mathrm{~Hz}$ over the course of several seconds. Would exciting the object at one of its lower resonance frequencies cause a multimode oscillation in the object, resulting in resonant lines not obscured by the excitation?

In fact, high frequency lines were repeatably observed to suddenly pop up as the excitation swept through certain critical low frequencies. This occurred whether there was an object in the field of excitation or not. Clearly what was being observed was the excitation of multimode responses within the experimental setup itself. None of the experiments with the margarita glass was ever observed to produce a line at one of the higher frequency resonances as the excitation was swept through one of the lower resonant frequencies. Sweeping from high to low frequency was also tried.

\subsubsection{Time-Windowed Periodic Excitation}

Another possibility that was explored was excitation with a time-windowed sinusoid. When the glass is plinked, the ringing response has a duration on the order of a second. On the other hand, the experimental setup has a very short impulse response.

In this set of experiments, the excitation was allowed to persist for relatively long duration. It was then abruptly zeroed out for a longer duration. This would allow time to enable the resonance response to build up, and to observe any decaying resonance response.

The response of interest is observed in the time domain. With no object in the field of view, it is expected that the wave would die out quickly after the excitation was zeroed out. When a resonant object whose decay rate is in the order of seconds is in the field of excitation, a weaker version of the signal should persist for a significant fraction of a second.

Figures 10 and 11 are typical results. Excitation was a triangle wave with a frequency of $3400 \mathrm{~Hz}$, and duration of 44 milliseconds. It was then zeroed out for 88 milliseconds. Figure 10 shows the response with no object in the field of excitation. The response is seen to die out fairly quickly, and to be completely decayed by the time the next excitation starts, 88 milliseconds later. This is exactly what would be expected for a low Q system. Figure 11 is the same experiment, with the margarita glass, with a $3400 \mathrm{~Hz}$ resonance and a nearly 1 second decay rate, in the field of excitation. The two results are virtually identical. The persistent signal in the time domain that would give evidence of a resonant response is not there. 


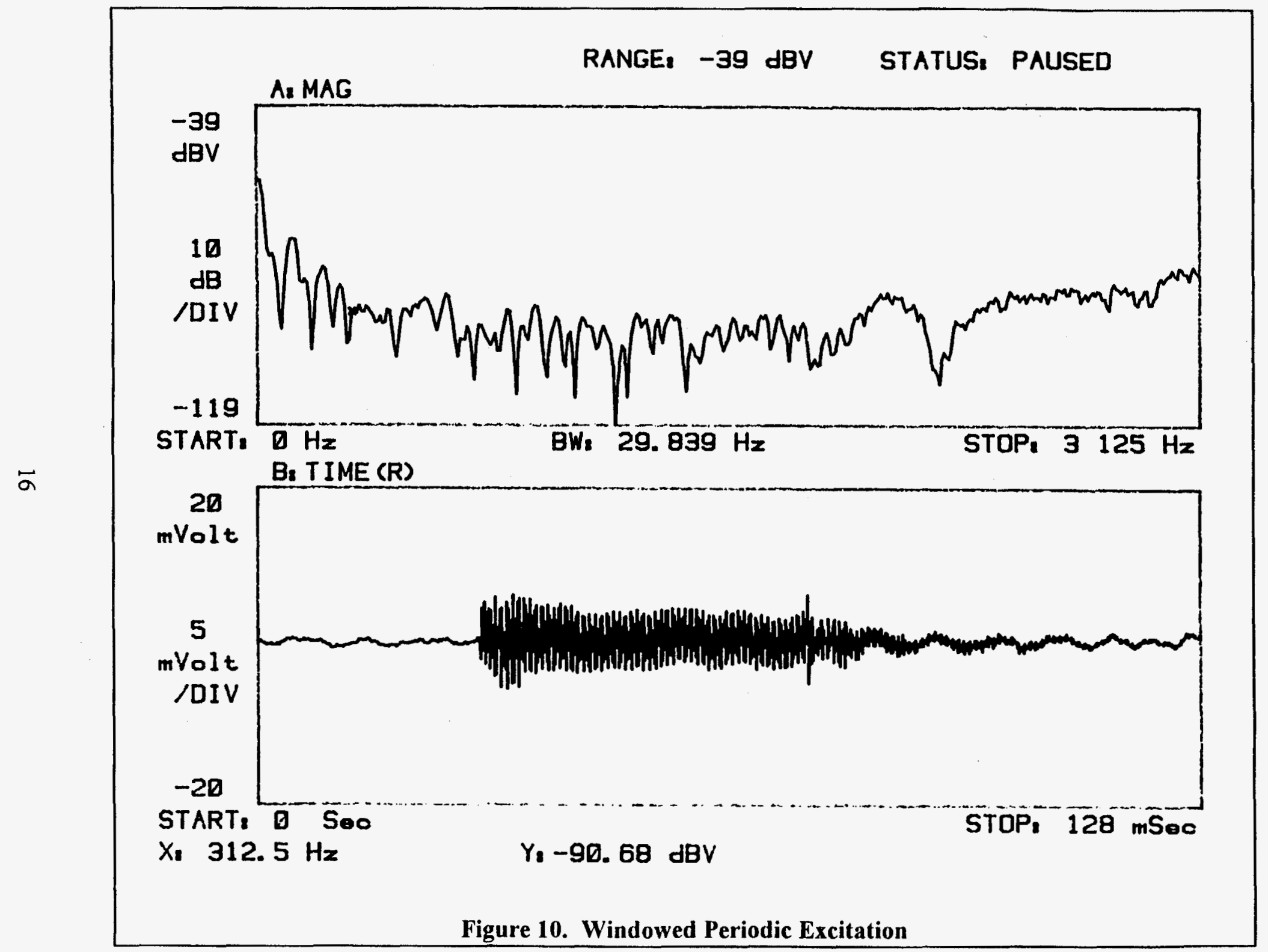




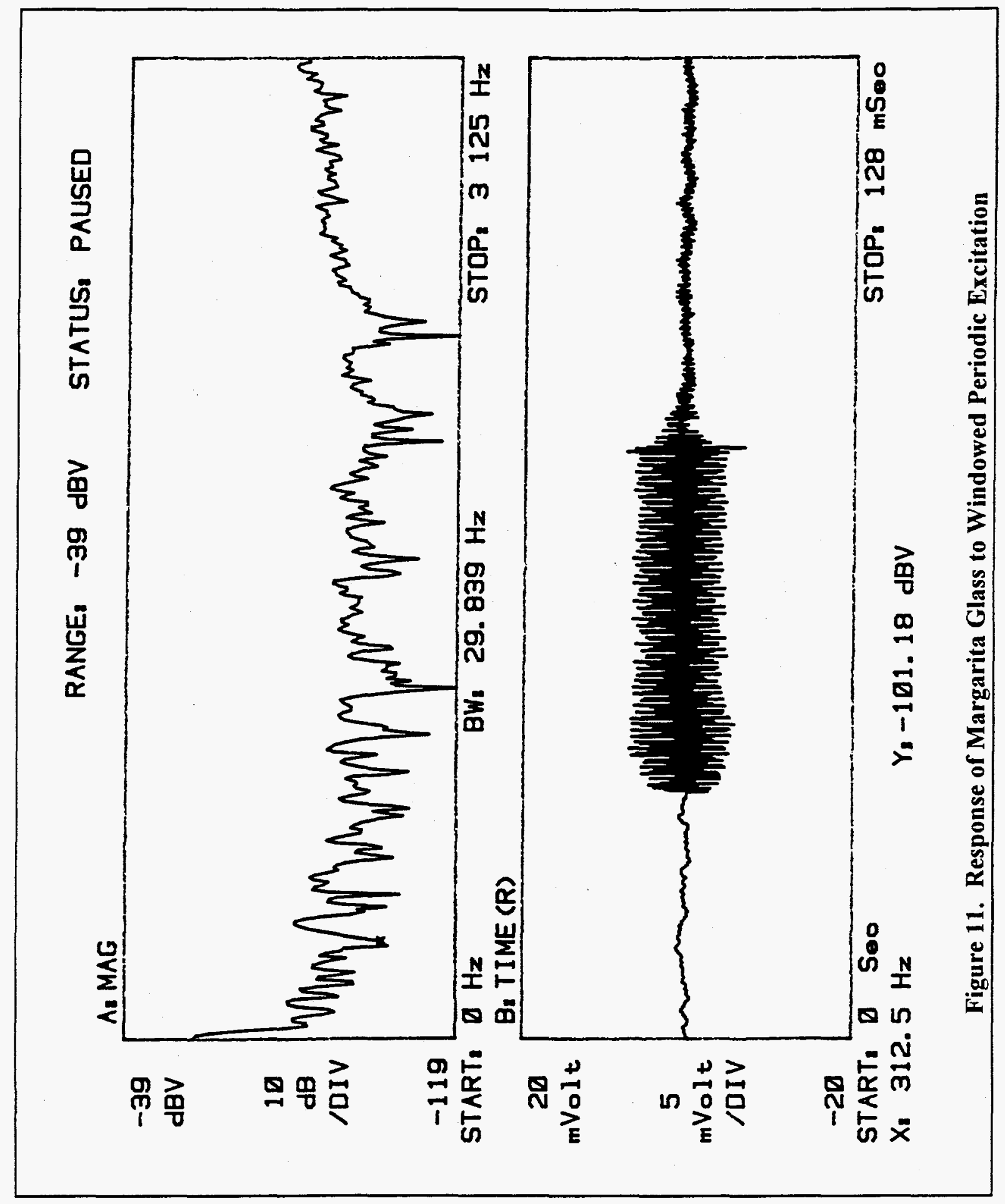


Among the variations that failed to produce a detectable response were the following. Single frequency excitation at 1150 and $1950 \mathrm{~Hz}$ was tried. Also, since the actual resonant response is a complex mode, a multi-component excitation containing $1150,1950,3400$, and $5200 \mathrm{~Hz}$ was tried.

Responses to windowed periodic excitation were also observed in the frequency domain. Here, the idea was to try the same thing that had been attempted with the swept sinusoid, to excite at one frequency in the hope of stimulating a multimode or harmonic response that would produce observable resonance lines at other frequencies. This was attempted with excitation at $1150 / 3,1150 / 2,1150,1950 / 3,1950 / 2,1950,3400 / 3,3400 / 2$, and $3400 \mathrm{~Hz}$. In other words, the three lowest resonant frequencies of the margarita glass, and several of the subharmonics of each, were tried, both with the glass in the field of view, and with the glass removed. In all these experiments the response spectrum with the glass in the field of excitation was indistinguishable from the spectrum without the glass present.

Do these experiments prove that it is impossible to excite an observable resonance by immersing the resonant object in an acoustic field? No, they do not prove it to be impossible. What these experiments do show is that, under laboratory conditions, with expensive equipment designed to behave in a nearly ideal manner, no practical way was found to use acoustic excitation to produce detectable resonant responses in an object known to have strong acoustic resonances.

These experiments suggest that this may not be a very practical method to detect mines. No practical way could be devised use acoustic waves to excite a strongly resonant object in open air. This suggests that it is even more impractical to use acoustic waves excite the weak resonances in a buried mine.

\subsection{Laboratory Shaker Tests}

Since this research did not uncover a practical way to excite resonances by acoustic waves, is there another way to excite resonances, such as shaking the ground?

A ground shaker operating at audio frequencies could be set up within a few feet of a suspected mined area. The resulting vibrations would not be sufficient to trigger a mine detonation, but might excite acoustic resonances in the mine. Such resonances should be easy to detect with a transducer and spectrum analyzer.

Shaker table experiments (Figure 5) were conducted on several non-metal objects. The shaker table can shake small objects at precisely controlled frequencies, and precisely controlled accelerations. The object under test is clamped to the shaker table.

The shaker table imposed limitations on the experiment. Acceleration of at least $0.2 \mathrm{~g}$ was required to collect meaningful data with the receiving setup. The shaker itself had a resonance at 
$1150 \mathrm{~Hz}$. Also, it was found that it was not practical to shake an object the size of a wine glass at frequencies higher than $2000 \mathrm{~Hz}$ for an acceleration of $0.2 \mathrm{~g}$.

Since the margarita glass also had a resonance at $1150 \mathrm{~Hz}$, and this interacted with the table resonance, no meaningful conclusions could be drawn from the margarita glass tests. A smaller wine glass was tried. Figure 12 shows the "plink" test for the wine glass mounted to the shaker. A resonance at $1400 \mathrm{~Hz}$ is clearly visible. This is the result of finger plinking the wine glass with the shaker table excitation turned off.

To observe the effect of the $1400 \mathrm{~Hz}$ resonance, excitation at $0.2 \mathrm{~g}$ was applied from 1250 $\mathrm{Hz}$ to $1600 \mathrm{~Hz}$ in steps of $50 \mathrm{~Hz}$. The responses of the empty shaker table are shown in Figure 13; a peak that is noticeably weaker than the others is at $1400 \mathrm{~Hz}$. The responses of the wine glass are shown in Figure 14.

The result was repeatable. These experiments were repeated numerous times for the wine glass and the empty shaker table. Figures 13 and 14 are typical of the data collected. Consistently, the empty table showed a $1400 \mathrm{~Hz}$ response substantially weaker than the responses at neighboring frequencies, while the wine glass showed a response in line with those at neighboring frequencies. That is, the presence of the wine glass and its $1400 \mathrm{~Hz}$ resonance consistently increased the 1400 response by $10 \mathrm{~dB}$ compared to when the wine glass was not present.

This is the only experimental evidence discovered in this project that suggests that an observable acoustic resonance could be excited by non-contact means. The effect is weak; the wine glass resonance increases the response at the resonant frequency by $10 \mathrm{~dB}$, and this was repeatably observable in these carefully controlled conditions. However, in the uncontrolled outdoor environment, a $10 \mathrm{~dB}$ resonant response does not stand out from the background. At least $20-30 \mathrm{~dB}$ increase in response due to resonance is needed to distinguish a resonance from natural variations in the background.

Several shaker tests were conducted with inert plastic mines. The plastic mines do not have strong resonances like a wine glass. Figure 15 shows the result of a plink test for a US NM-M14 anti-personnel mine mounted in a shaker. No resonance lines stand out. Figure 16 shows a shaker test with the NM-M14 mine mounted in the shaker with $0.2 \mathrm{~g}$ acceleration applied from 800 to $1600 \mathrm{~Hz}$ in steps of $50 \mathrm{~Hz}$. Figure 17 shows a shaker test with a Soviet PMN anti-personnel mine mounted in the shaker with $0.2 \mathrm{~g}$ acceleration applied from 800 to $1600 \mathrm{~Hz}$ in steps of $50 \mathrm{~Hz}$. The response patterns are repeatable for each mine, and they are different from each other. However, there is no evidence that these are resonance effects, and there is not enough variation to make them stand out from natural variations in the environment. 


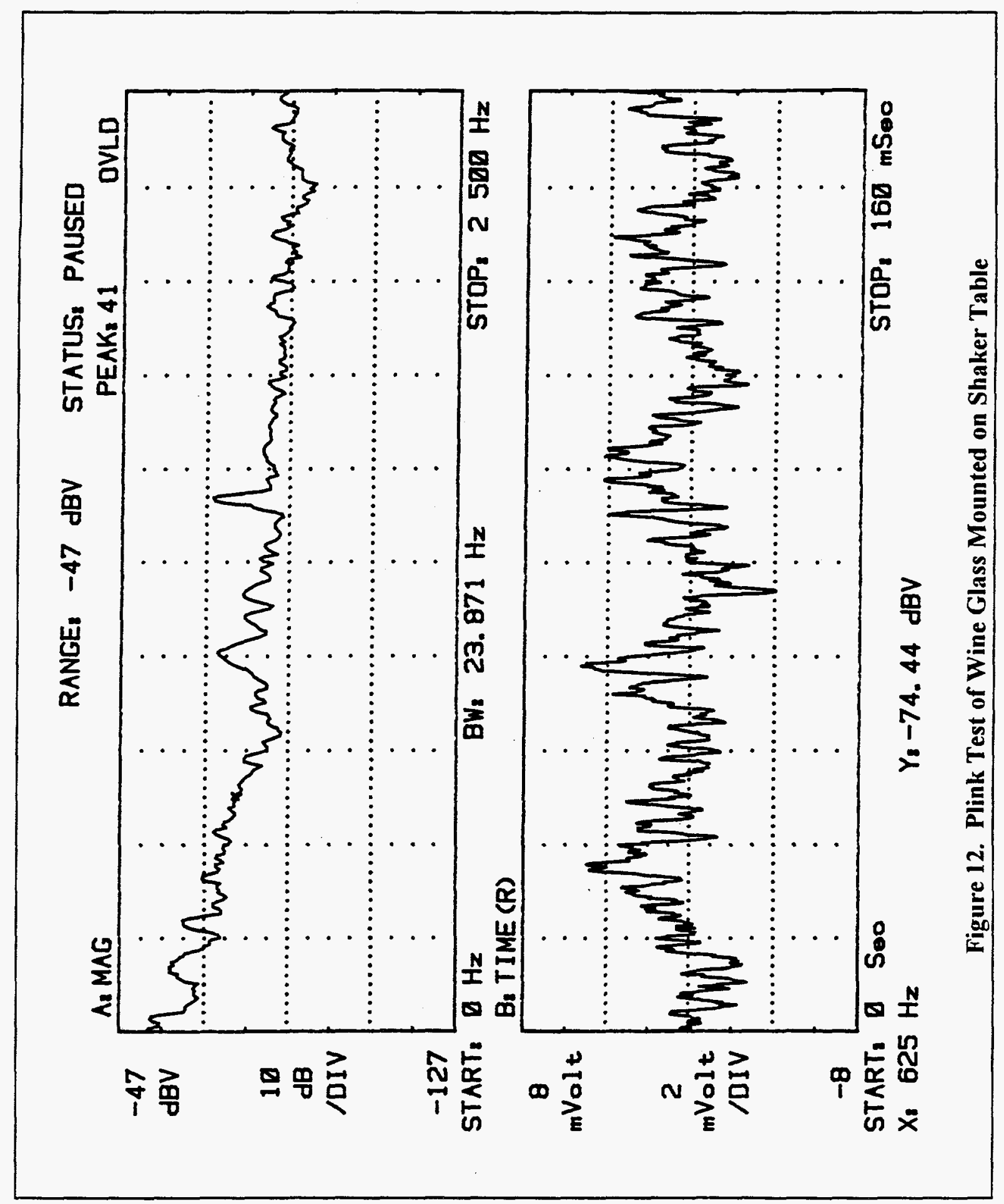




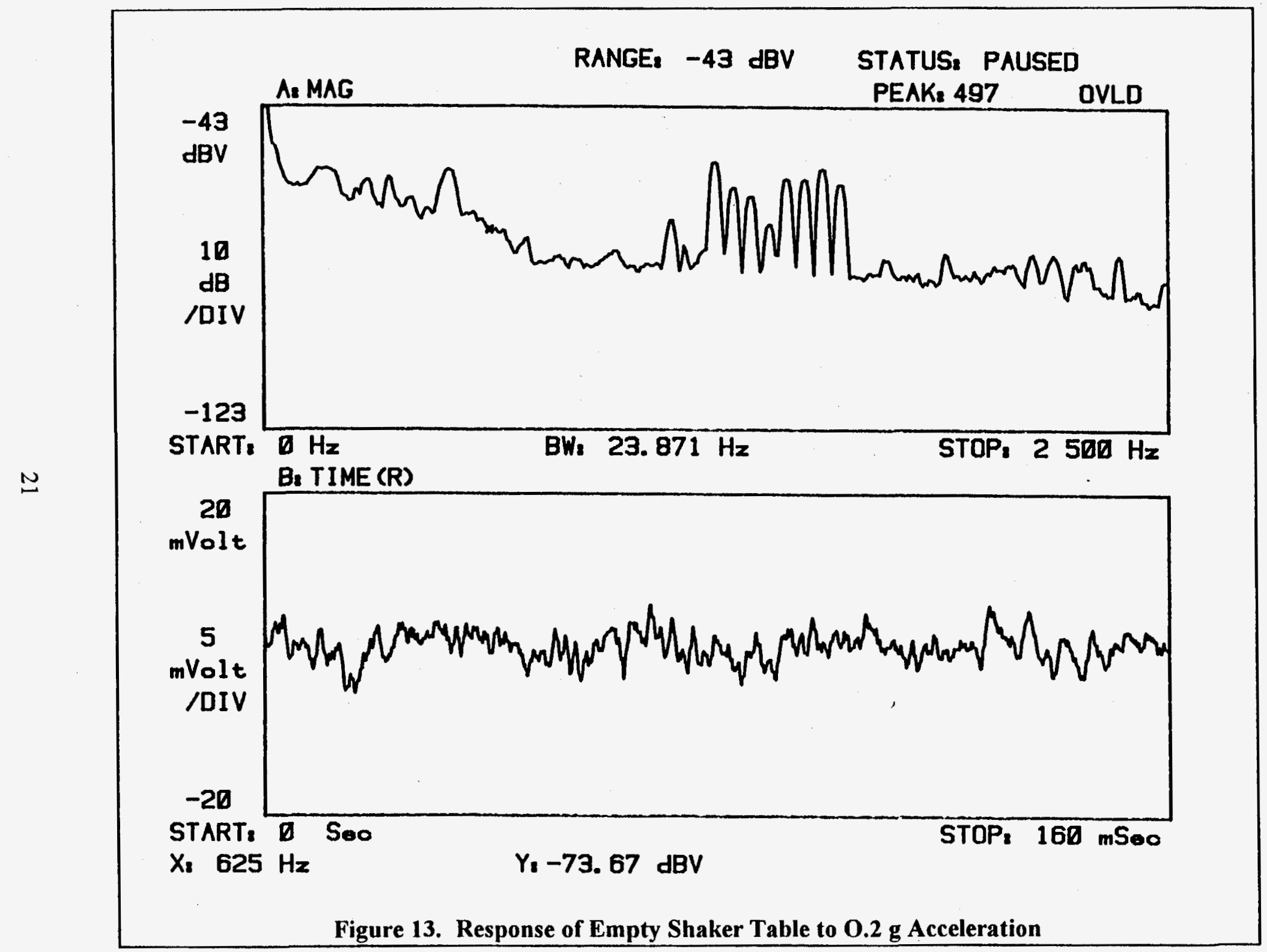




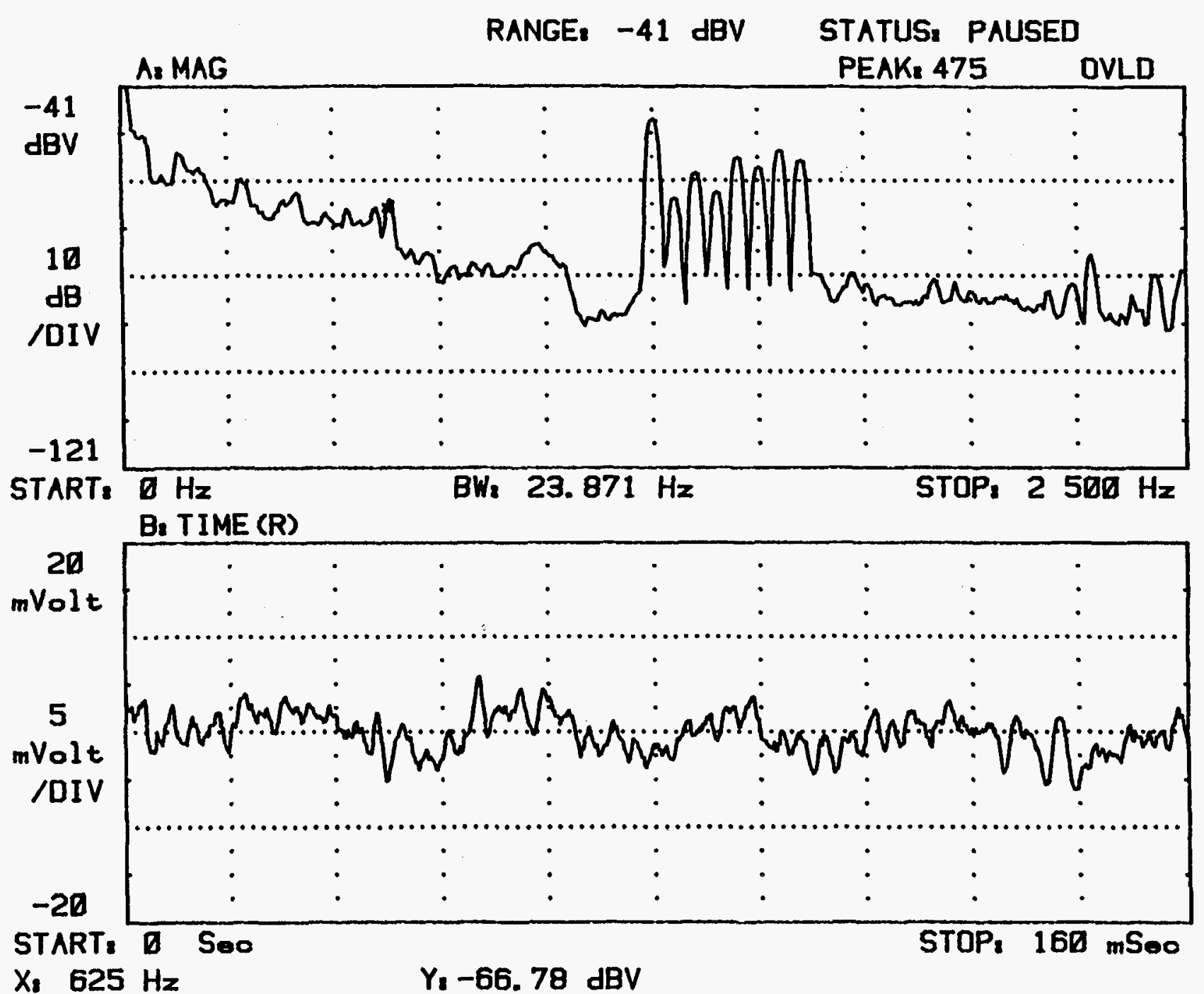

Figure 14. Response of Wine Glass to $0.2 \mathrm{~g}$ Acceleration 


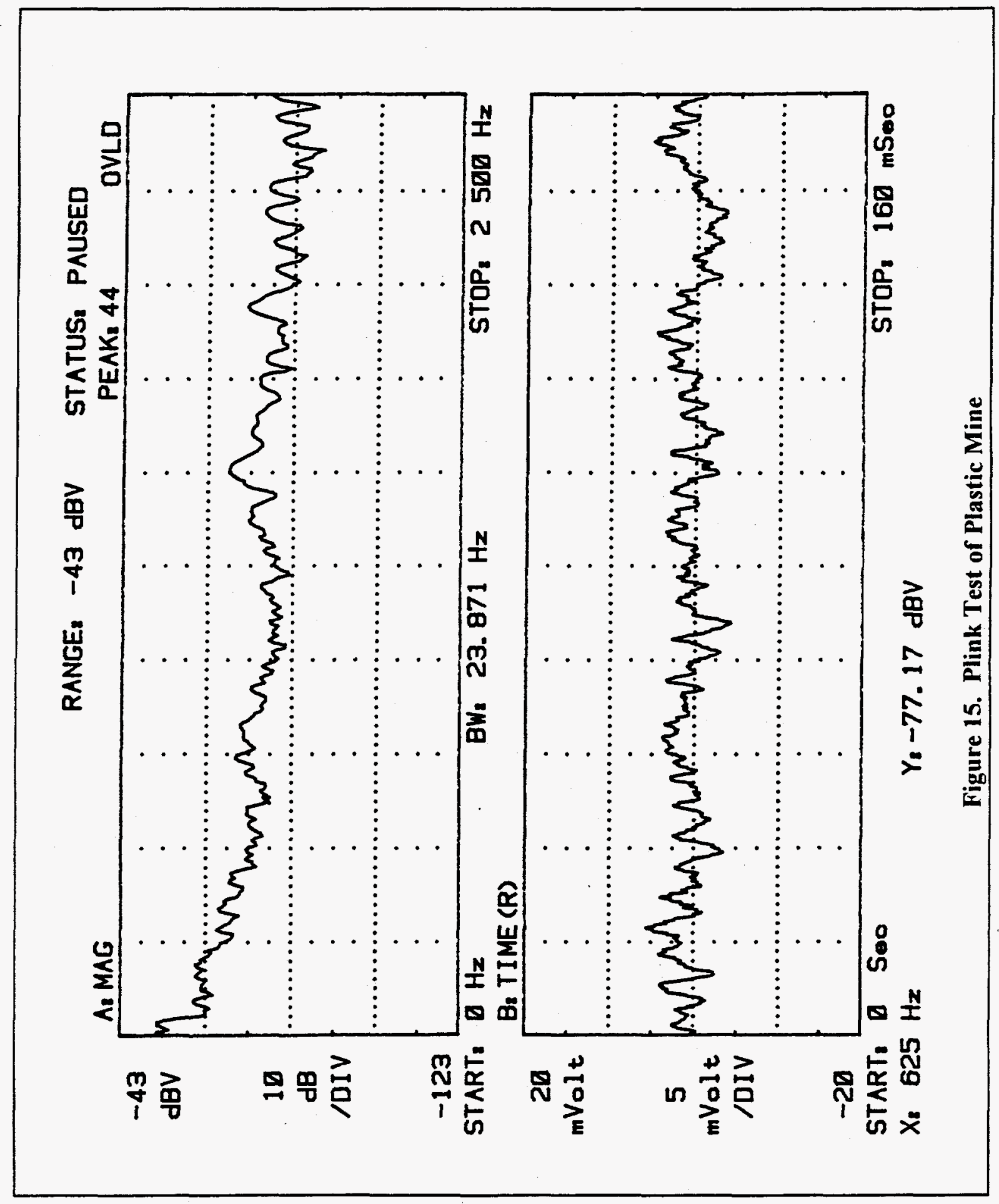




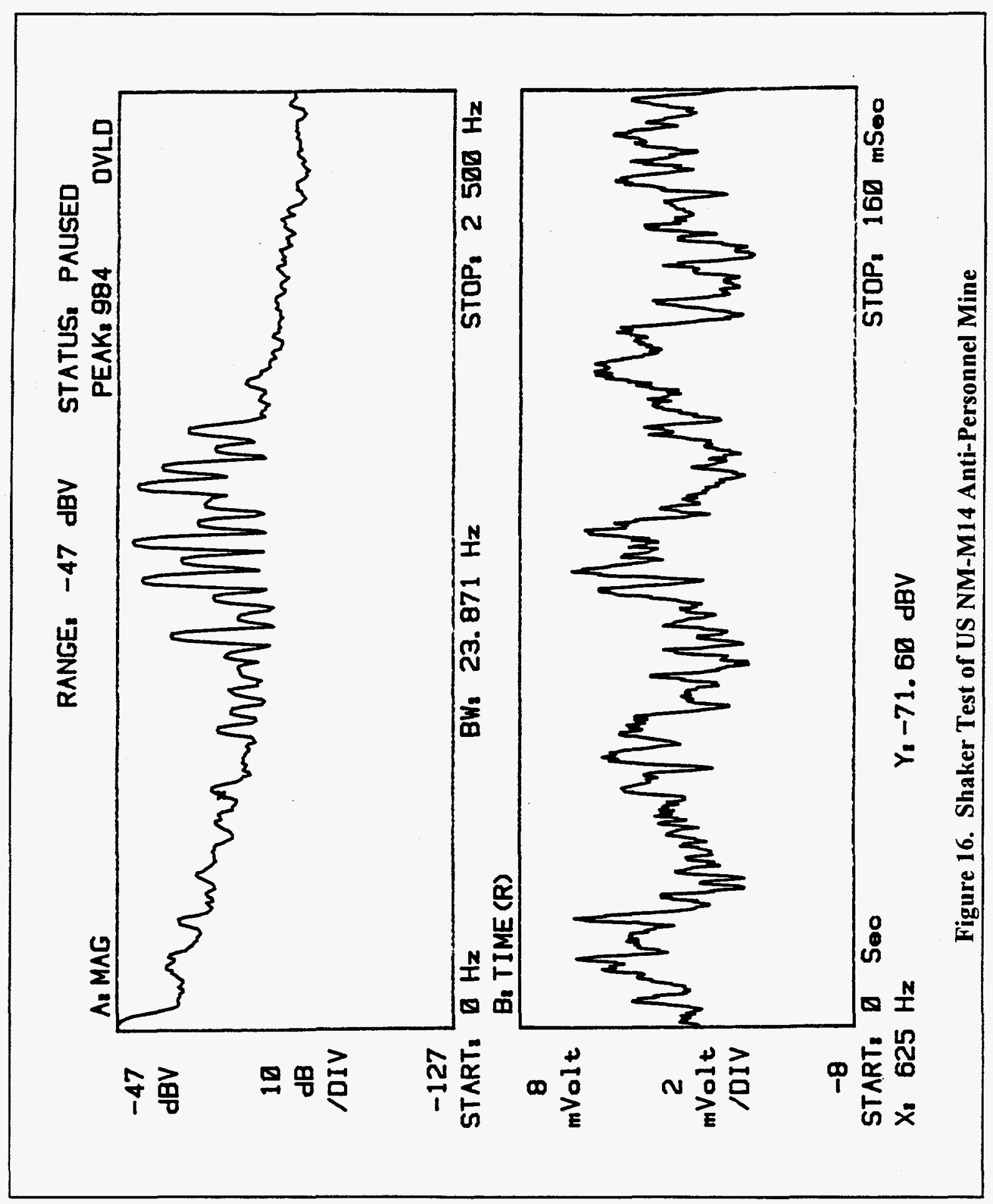




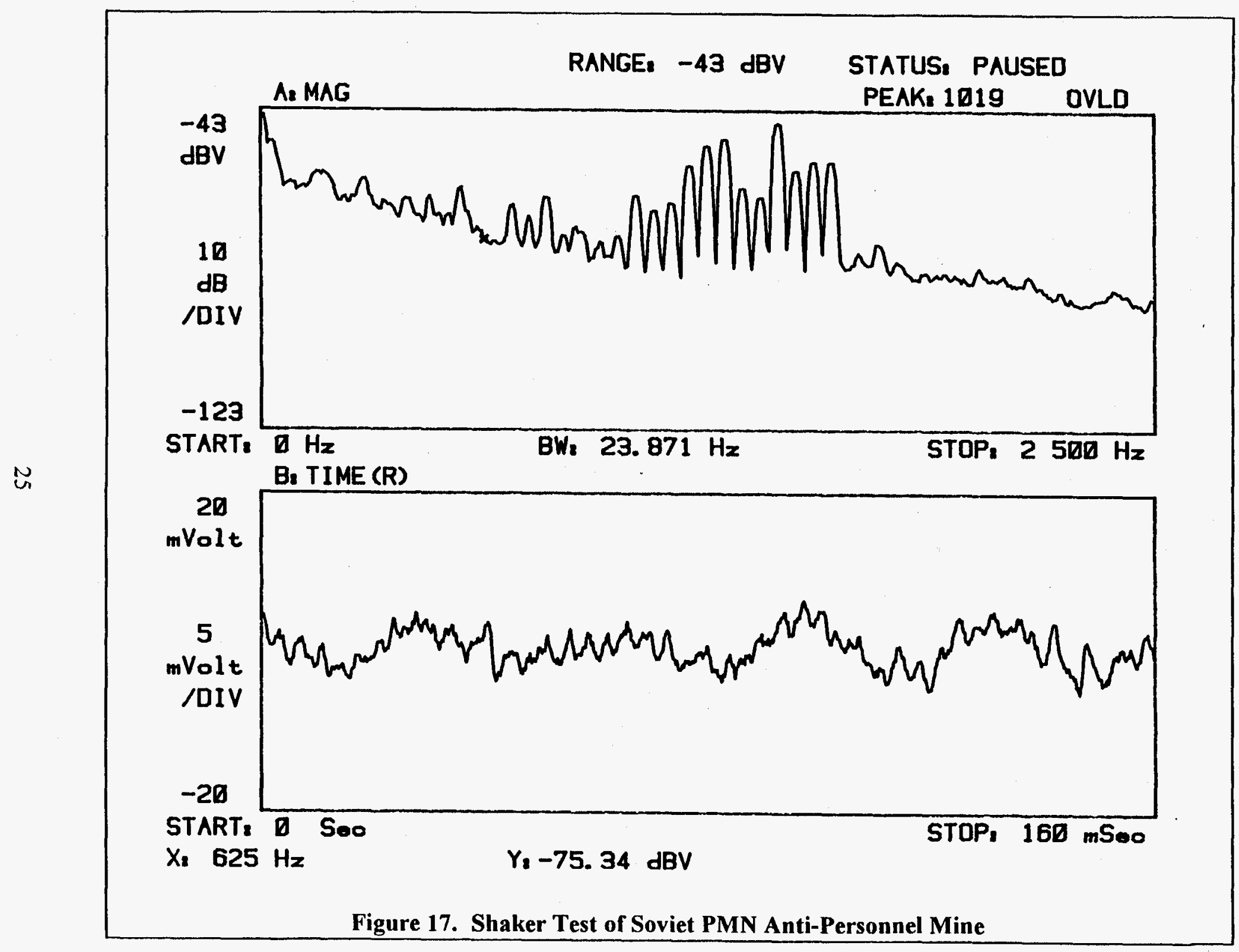




\subsection{Field Tests}

Several field tests were conducted at the 800 Area of the Oak Ridge National Laboratory reservation. There are several issues that could only be addressed by outdoor tests. These include the variability of propagation conditions in the ground, the cutoff frequency of soil, and the attenuation of the soil.

The first experiment (Figure 2) did not take leakage through air into account. Three holes were dug, with the excitation horn placed in the first hole which was left open. The object under test buried in the next. The microphone pickup placed in the third hole which was also left open. The acoustic energy that leaked from the excitation horn to the microphone through the open air completely overwhelmed any signals that might have propagated through the ground.

Heavy shielding was used for subsequent experiments. The excitation horn was surrounded with sound deadening material, and its output directly butted to the face of the ground. This maximized the energy being coupled into the ground, and minimized the energy coupled into the surrounding air. For sound deadening, a heavy tarpaulin covered the hole that contained the microphone pickup. These experiments were done on the first clear day after a week of heavy rain; the ground was saturated with water, and the propagation conditions were as favorable as possible.

To get an idea of the effect of the soil on the signal, the results of applying excitation through open air and the ground were compared. Figure 18 shows the result of feeding excitation from the horn to the microphone pickup through three feet of open air in the outdoor setting. The excitation is a sinusoid whose amplitude voltage into the horn was fixed, and whose frequency was swept continuously from $1 \mathrm{kHz}$ through $30 \mathrm{kHz}$, and the response seen to roll of with increasing frequency.

Figure 19 shows the effect of the soil. The same swept excitation was used in Figure 19 as was used in Figure 18. The propagation path is two feet of soil saturated with water. Figure 19 shows that in the passband from $1 \mathrm{kHz}$ to $4 \mathrm{kHz}$ the soil attenuation is about $35 \mathrm{~dB}$ greater than the open air path. The loss is substantial, but tolerable. Above $4 \mathrm{kHz}$, the response rolls off, and drops below the noise floor of the receiving electronics above $8 \mathrm{kHz}$.

In Figure 20 the experimental geometry is the same as for Figure 19. The excitation was a sinusoid of fixed amplitude at discrete frequencies from $1 \mathrm{kHz}$ to $13 \mathrm{kHz}$ in steps of $1 \mathrm{kHz}$. The signal is clearly discernable through $8 \mathrm{kHz}$ and then drops abruptly by $20 \mathrm{~dB}$. Low frequency acoustic effects propagate through several feet of soil, but ultrasonic effects do not. These wet soil conditions were very favorable for sound propagation; dry soil would have done even worse. 


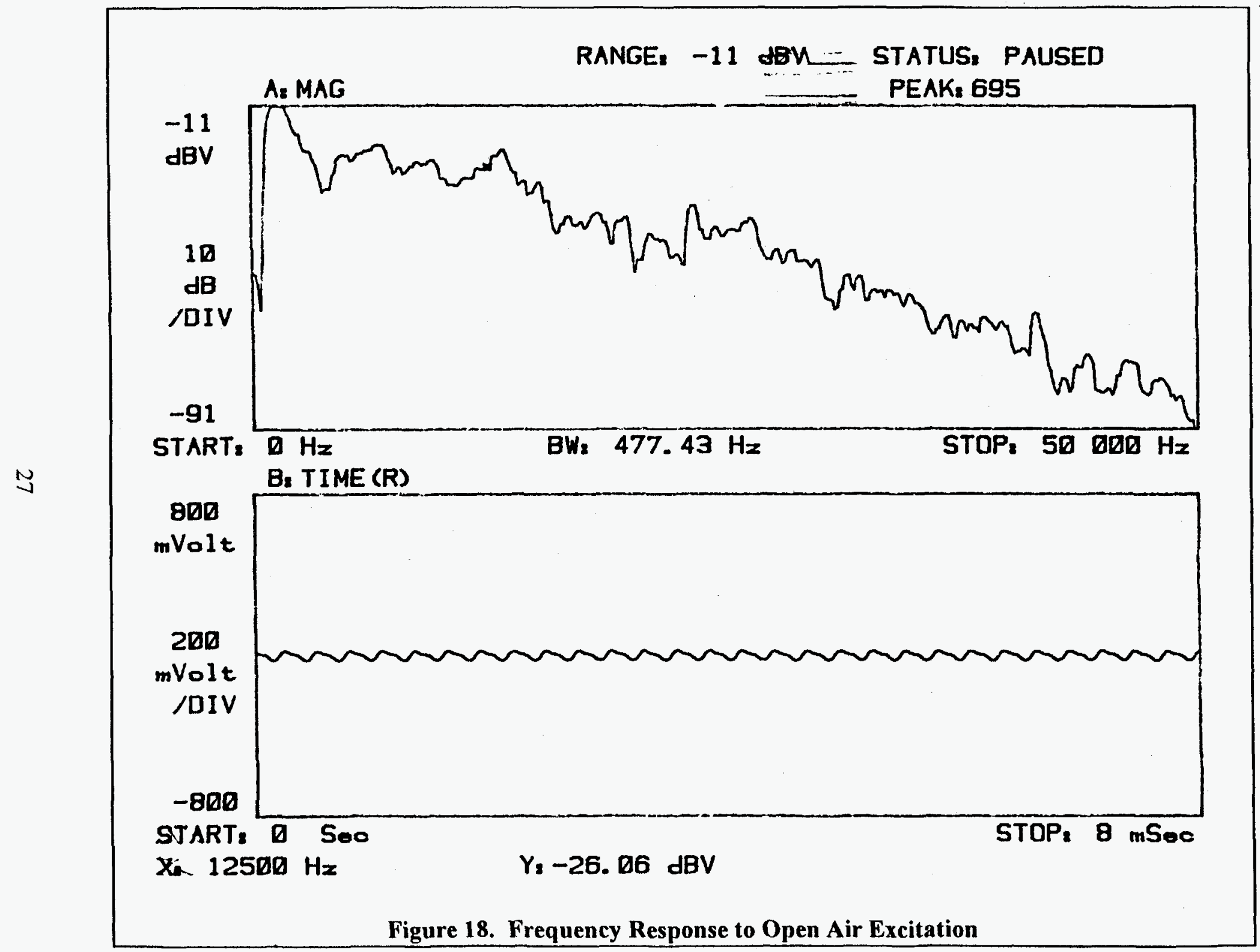




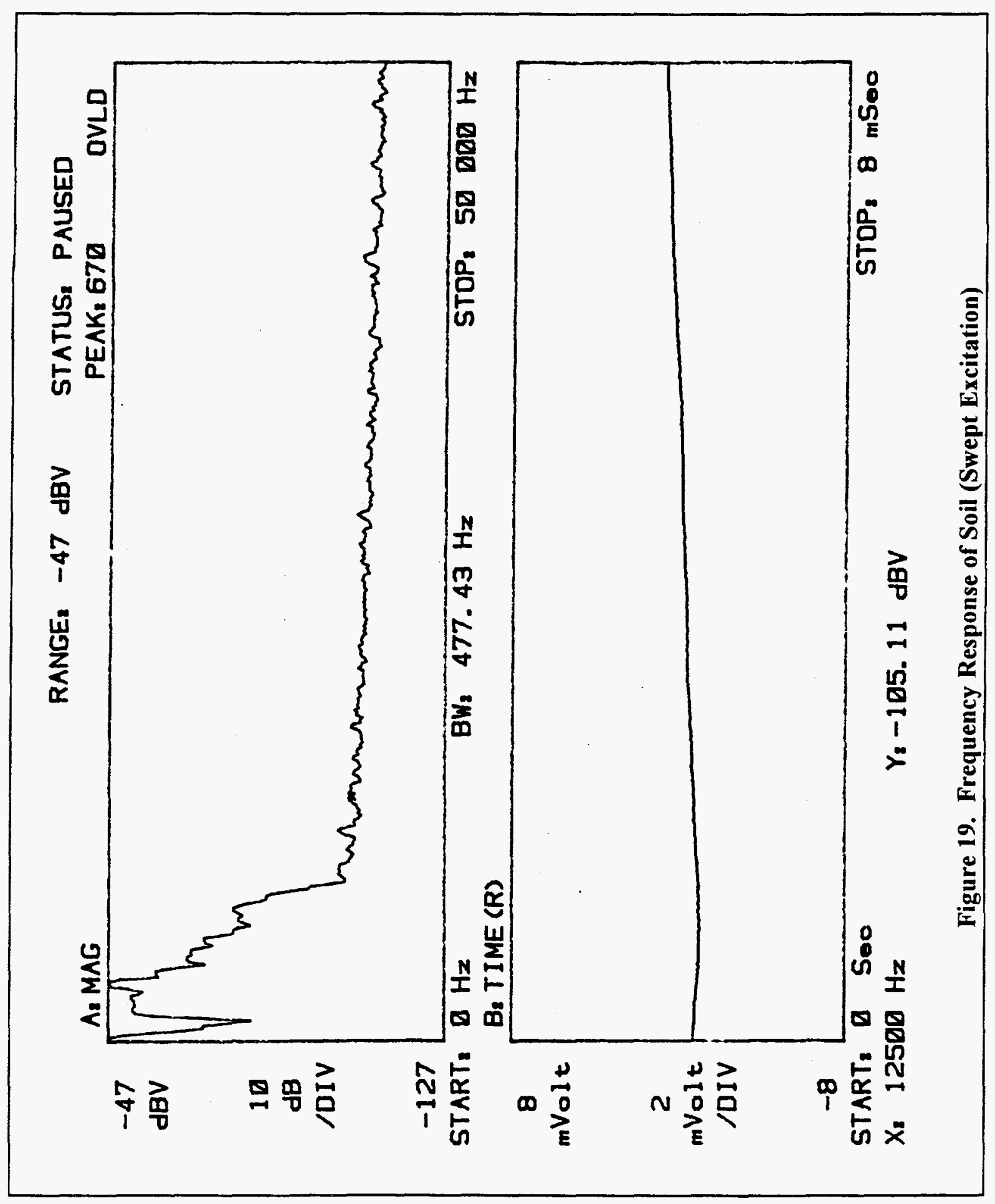




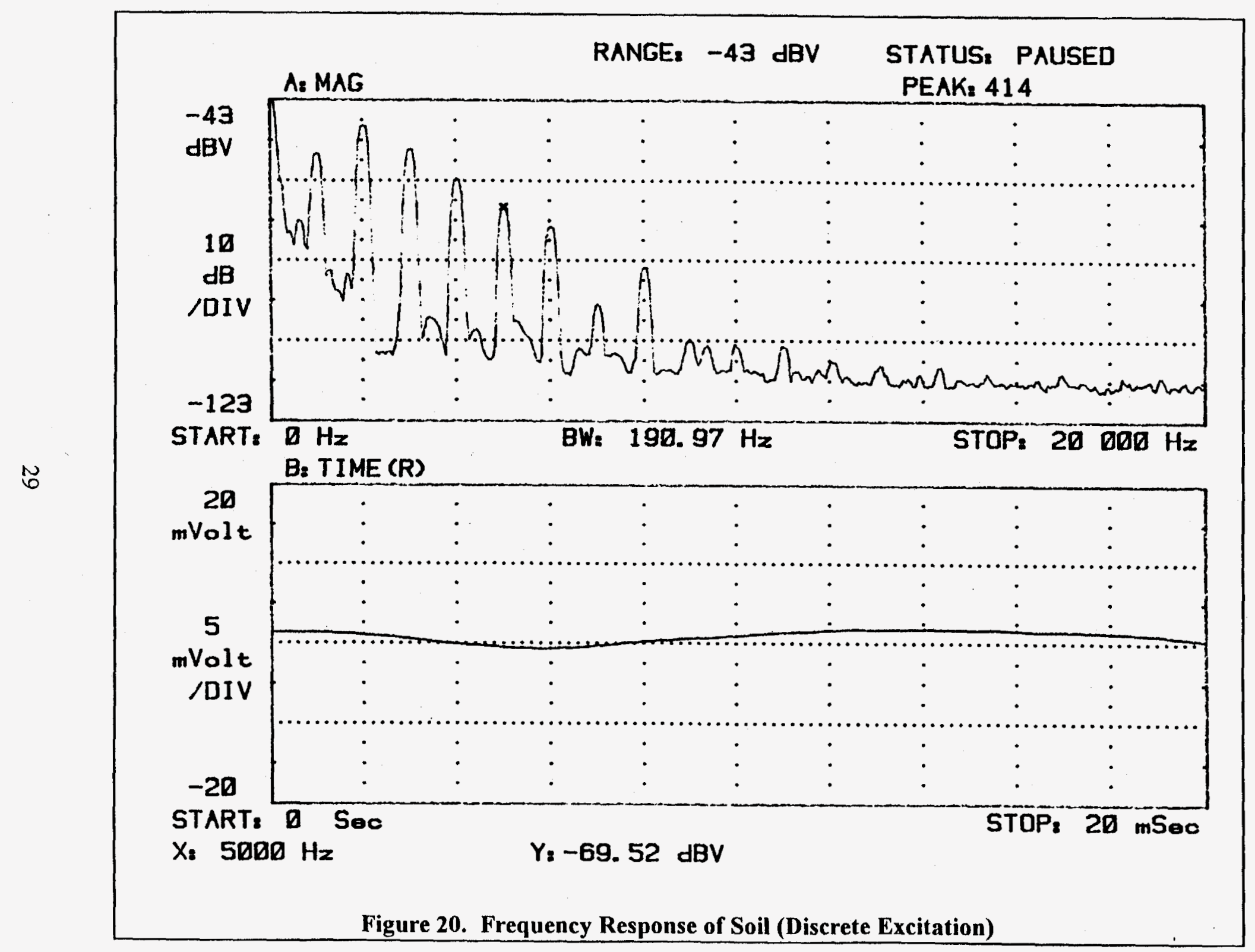


It is also noteworthy that when the same experiment is repeated with the microphone in another hole, also two feet from the excitation source, the transfer function looks similar in the passband, but not identical. Small changes in the location in the ground cause non-trivial changes in the frequency response. For this reason, dielectric objects cannot be detected by looking for subtle changes in the soil transfer function. A practical detection effect would have to be strong enough to be detectable against a background of the normal variations in the environment.

Another issue addressed by the outdoor experiments was whether or not acoustic resonant responses propagating through the ground are detectable. Figure 21 shows that they are. In Figure 21, the pickup microphone was placed in a hole covered by a tarpaulin folded into many layers. On the surface of the ground, the excitation horn with its heavy shielding was placed between pickup hole, and the target hole. Two feet away from the microphone pickup, a plastic canister was placed in the target hole, and the margarita glass was placed in the canister. The margarita glass was plinked with a plastic pen. The response, detected through two feet of soil is shown in Figure 21. This experiment was repeated several times and Figure 21 is typical. If the resonance can be excited, it is possible to detect it through several feet of soil.

Another issue to be addressed by the outdoor tests was whether or not it is practical to use acoustic excitation to stimulate acoustic resonances in a buried object. To simulate a hypothetical non-metal mine with strong acoustic resonances, the margarita glass was placed in a plastic canister, and the canister was buried between the excitation horn and the pickup microphone hole. The horn was placed vertically such that its output was directly butt-coupled into the ground. After filling in the hole containing the canister, it was covered by a heavy tarpaulin folded into many layers. The hole containing the pickup microphone was also covered by a heavy tarpaulin folded into many layers. Several different wavelet and swept acoustic excitation patterns were tried. None produced detectable resonances. This result was not unexpected, since acoustic excitation also failed to produce detectable resonant responses in more controlled setting of the indoor laboratory.

The final issue to be considered was whether or not the resonance could be stimulated by impulsive excitation as suggested in the JASON's report. To test this, the same experimental setup was used as described in the previous paragraph. However, the excitation was provided by repeatedly slapping the ground hard with the flat of a long handled shovel, the location of impact being approximately three feet from the buried object. Figure 22 shows the response of the margarita glass in the plastic canister. Figure 23 shows the response with the target removed and the hole backfilled. The resonances of the margarita glass cannot be distinguished from the background responses of the environment. It must be remembered that this experiment was contrived to use an object known to have much stronger resonances than those that might be found in a plastic mine. If there is a practical way to excite acoustic resonances in buried objects, it is expected to be radically different from the methods tried in this project. 


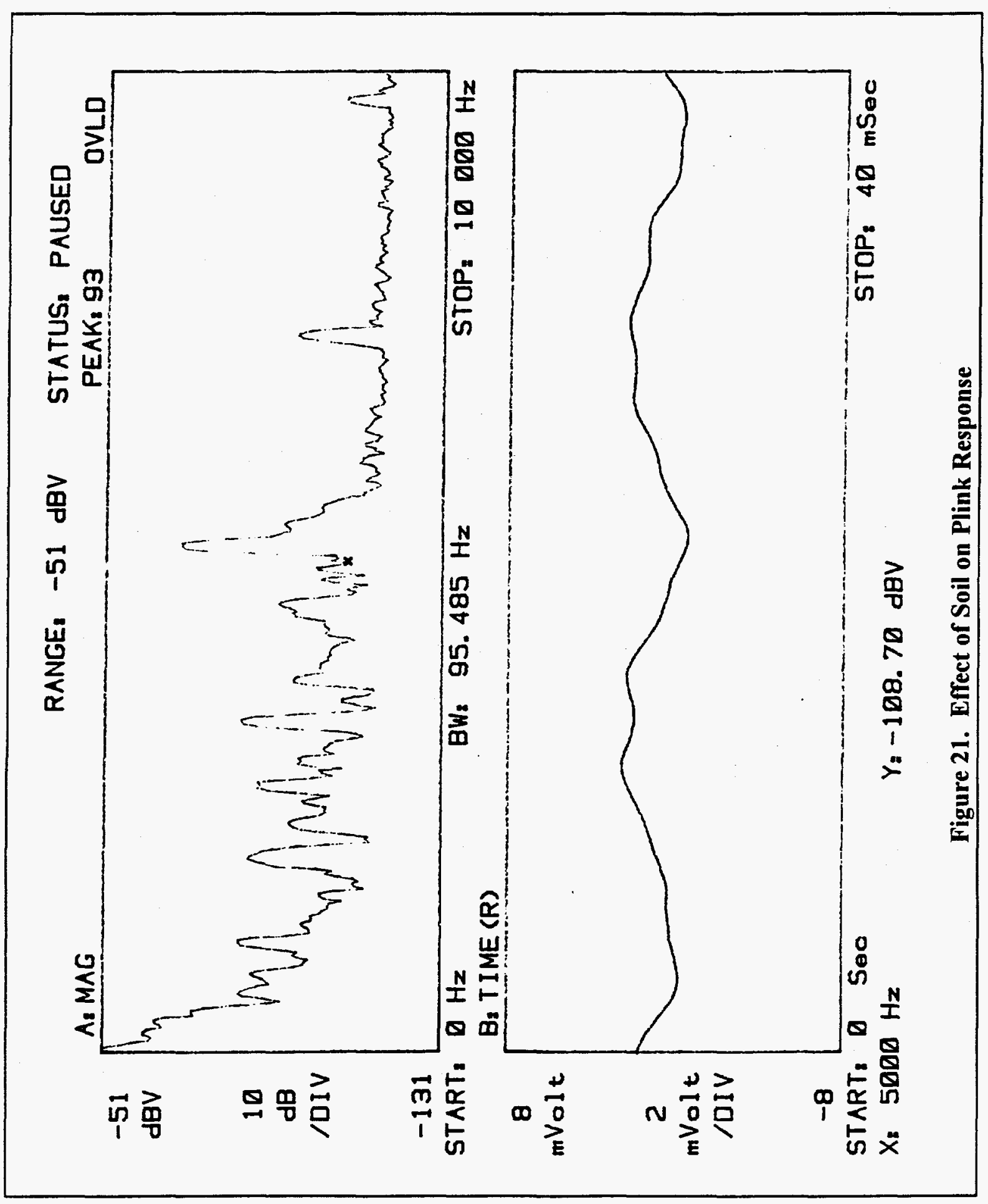




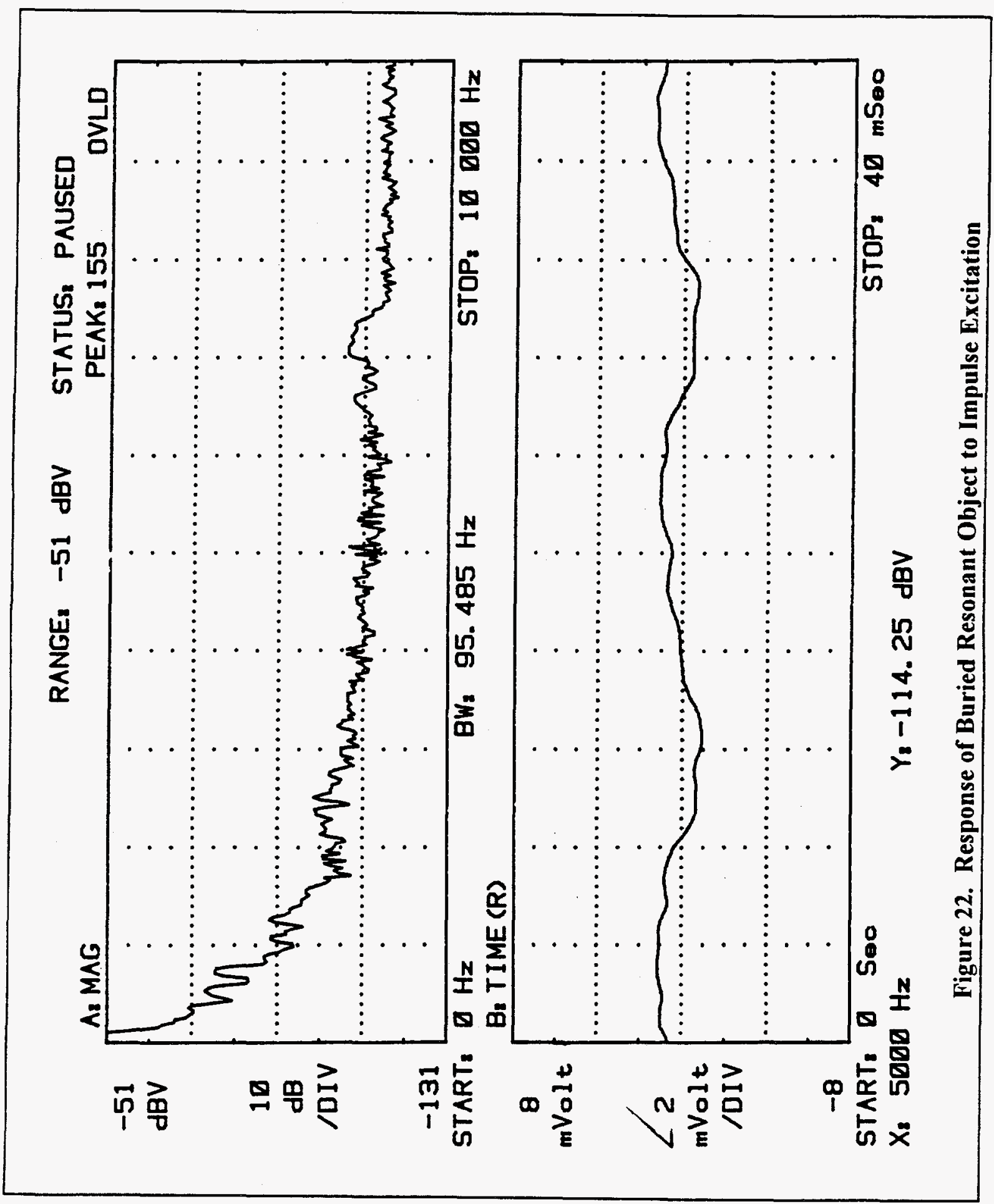




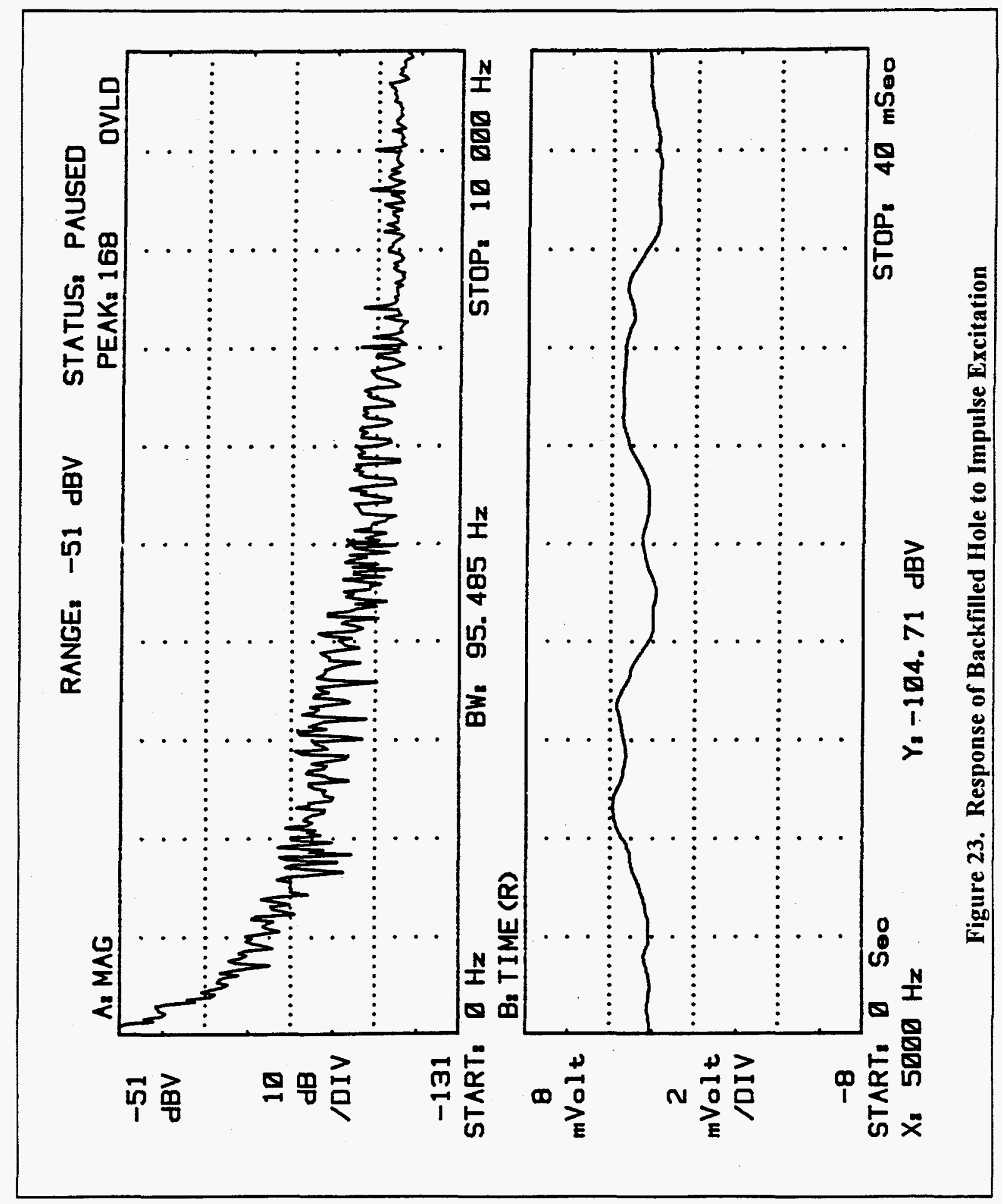




\section{CONCLUSIONS}

The idea of detecting mines by ultrasonic effects is out of the question. The best underground propagation is below $4 \mathrm{kHz}$. Even under the most favorable conditions, through two feet of soil, signals above $8 \mathrm{kHz}$ are attenuated to below the noise floor of the receiving electronics. Any mine detecting technique based on acoustic effects must be done at audio frequencies.

Subtle changes in the transfer function of the soil due to the presence of a buried object are not a reliable distinguishing feature. The transfer function of the soil changes non-trivially even with small changes in location. A stronger effect must be used. Resonances should be a distinguishing feature strong enough be detected if they can be excited.

At low audio frequencies, the effect of two feet of soil is to introduce approximately 35 $\mathrm{dB}$ of path loss as compared to open air propagation. The $5200 \mathrm{~Hz}$ resonance of a non-metal object stimulated by direct impulse was readily detectable through two feet of soil.

Leakage of the acoustic excitation through the air was a major source of disruption in the outdoor experiments in this project. Elaborate shielding methods were required to assure that what was being detected really was the signal propagating through the ground. Such elaborate sound shielding would probably be impractical in a humanitarian demining setting.

Although acoustic resonant responses (if they exist) are relatively easy to detect, they are very difficult to excite by the non-contact means that must be used for buried objects. Despite many different attempts, this project did not discover any practical means of using sound to excite resonant responses in objects known to have strong resonances. The shaker table experiments did see an effect that might be attributable to the resonance of the object under test, but the effect was weak, and exploited the a priori knowledge of the resonant frequency of the object under test to distinguish it from the background. If experiments that used objects known to have strong acoustic resonances produced such marginal results, this does not seem to be a practical method to detect objects with weak or non-existent resonances.

Several representative inert plastic mines were tested. They did not exhibit any detectable acoustic resonances, even in response to direct plinking and shaker table excitation. It is worthwhile to keep in mind what an inert mine is. It is a regular mine with the explosive removed. Inert mines, which actually had hollow spaces that might allow resonances to form, exhibited no detectable resonances. This suggests that live mines, whose hollow spaces are filled with explosive, are even less likely to exhibit resonances.

The objective of this project was to investigate whether or not acoustic resonance is a feasible means of detecting buried plastic mines. It does not appear to be so. Plastic mines do not have strong acoustic resonances. Even when an object has a strong resonance, it is very difficult to excite by non-contact means. Even if a way could be found to excite the resonance, the response is very likely to be masked by leakage of excitation energy through the air to the pickup. 


\section{ACKNOWLEDGMENTS}

This research was funded through the Seed Money Program of the Laboratory Directed Research and Development Fund at ORNL. The author thanks the ORNL Seed Money Committee for their support. 


\section{REFERENCES}

1. Hanshaw, T., "Multi-sensor fusion for the detection of mines and 'mine like' targets," in Detection Technologies for Mines and Minelike Targets, Abinash C. Dubey, Editor, Proc SPIE 2496, pp. 152-158 (1995).

2. Strada, G. "The Horror of Landmines," Scientific American, May 1996, pp. 40-45.

3. Dugan, R., "Detection of Landmines and Unexploded Ordinance by Exploitation of the Chemical Signature," presented at DARPA UXO Detection by the Chemical Signature Conference, Arlington VA, 3 June 1996.

4. Terror in the Mine Fields, Program \#2301 on the Nova TV series on PBS, WGBH Boston (1996).

5. Barnard, R.L., "Mine detection technologies essential to survivability," in Detection Technologies for Mines and Minelike Targets, Abinash C. Dubey, Editor, Proc SPIE 2496, pp. 206-207 (1995).

6. Horowitz, P., et. al., New technological approaches to humanitarian demining, Draft Report JSR-96-115, JASON, The MITRE Corporation, McLean VA, August 1996. 
ORNL/TM-13514

\section{INTERNAL DISTRIBUTION}

1. F. H. Akers

2. G. T. Alley

3. R. G. Gilliland

4. R. A. Hess

5. S. W. Kercel

6. J. M. Jansen, Jr.

7. D. W. McDonald

8. B. S. Hoffheins
9. T. P. Sjoreen

10. R. W. Tucker, Jr.

11. J. D. White

12. Central Research Library

13. Y-12 Technical Reference Section

14. Laboratory Records-Record Copy

\section{EXTERNAL DISTRIBUTION}

15. Dr. Andrew Hibbs, Quantum Magnetics, Inc., 7740 Kenamar Court, San Diego, CA 92121-2425

16. Ron Moore, The RM Group, Inc., 12024 Broadwood Drive, Knoxville, TN 37922

17. David Norton, Houston Advanced Research Center, 4800 Research Forest Drive, The Woodlands, TX 77381

18. Michael F. O'Connell, U. S. Department of Energy, Office of Non-Proliferation and National Security (NN20), 1000 Independence Avenue SW, Washington, D.C. 20585-0420

19. Chris O'Donnell, Joint UXO Coordinating Office, ATTN: AMSEL-RD-UXO-CO, 10221 Burbeck Road, Fort Belvoir, VA, 22060-5806

20. M. M. Sevik, Carderock Division, Naval Surface Warfare Center, Code 70, Bethesda, MD 20084-5000

21. Ernesto Suarez, Pratt \& Whitney, P.O. Box 109600, Mail Stop 716-87, West Palm Beach, FL 33410-9600

22-23. Office of Scientific and Technical Information, U.S. Department of Energy, P.O. Box 62, Oak Ridge, TN 37831 